\title{
Impaired Migration in the Rostral Migratory Stream But Spared Olfactory Function after the Elimination of Programmed Cell Death in Bax Knock-Out Mice
}

\author{
Woon Ryoung Kim, ${ }^{1}$ Younghwa Kim, ${ }^{1}$ Bokkee Eun, ${ }^{1}$ Ok-hee Park, ${ }^{1}$ Hyun Kim, ${ }^{1}$ Kyungjin Kim, ${ }^{2}$ Chang-Hwan Park, ${ }^{3}$ \\ Sharon Vinsant, ${ }^{4}$ Ronald W. Oppenheim, ${ }^{4}$ and Woong Sun ${ }^{1}$ \\ ${ }^{1}$ Department of Anatomy, College of Medicine, Korea University, Sungbuk-Gu, Seoul 136-705, Korea, ${ }^{2}$ School of Biological Sciences, College of Natural \\ Sciences, Seoul National University, Shilim-Dong, Kwanak-Gu, Seoul 151-742, Korea, ${ }^{3}$ Department of Microbiology, Hanyang University College of \\ Medicine, Haeng Dang-Dong, Sung Dong-Gu, Seoul 133-791, Korea, and ${ }^{4}$ Department of Neurobiology and Anatomy and Neuroscience Program, Wake \\ Forest University School of Medicine, Winston-Salem, North Carolina 27157
}

Rats and mice exhibit neurogenesis of olfactory bulb (OB) interneurons throughout adulthood. To homeostatically maintain stable neuron numbers, it is necessary to continuously remove a subset of $\mathrm{OB}$ neurons by programmed cell death (PCD). Here we demonstrate that Bax is critical for the elimination of $\mathrm{OB}$ neurons by showing that Bax-KO mice exhibit greatly reduced PCD in the OB. Despite the reduction of $\mathrm{PCD}$, however, proliferation of progenitors and the size of the OB were virtually unaffected in Bax-knock-out (KO) mice. However, reducing PCD by Bax deletion affected the migration of a subset of adult-produced neurons by the disruption of glial tube formation as well as by premature detachment of neuroblasts from the migratory chain. Rescued cells aberrantly remained in the subventricular zone (SVZ)-rostral migratory stream (RMS), in which they differentiated into calretinin ${ }^{+}$or GABA-expressing interneurons. Because of the migratory deficit, $\mathrm{OB}$ cell homeostasis involving new cell entry and $\mathrm{PCD}$ (neuronal turnover) was virtually absent in adult Bax-KO mice. Despite this, Bax-KO mice exhibited normal olfactory behaviors such as odor discrimination and olfactory memory which are thought to be influenced by adult neurogenesis. These results demonstrate that PCD is involved in the regulation of RMS migration and differentiation after $\mathrm{OB}$ neurogenesis, but that animals maintain normal olfactory function in the absence of PCD.

Key words: neurogenesis; Bax; cell death; olfactory bulb; migration; behaviors

\section{Introduction}

The olfactory bulb is one of the few brain regions in which new neurons are continuously added throughout life (Altman, 1969; Kaplan et al., 1985; Garcia-Verdugo et al., 1998; Gage, 2002; Hack et al., 2005). The neural stem cells which produce the olfactory interneurons in the adult brain mainly reside in a specialized cellular niche located in the anterior subventricular zone (SVZ) of the lateral ventricle (Doetsch et al., 1999), although a subset of new $\mathrm{OB}$ interneurons also appear to be produced more rostrally (Gritti et al., 2002; Liu and Martin, 2003). Newly produced postmitotic neuroblasts migrate toward the olfactory bulb $(\mathrm{OB})$ via the rostral migratory stream (RMS) (Lois and Alvarez-Buylla, 1994; Lois et al., 1996). A morphologically mature RMS appears within 1 month after birth, and newly produced neuroblasts

Received Aug. 23, 2006; revised Nov. 6, 2007; accepted Nov. 16, 2007.

This work was supported by Korean Ministry of Science, Technology Grants M10412000078-04N1200-07810 (W.S.) and M10641280003-06N4128-00310 (W.S.) and National Institutes of Health Grants NS20402 and NS048982 (R.W.O.). Some of the experiments were technically supported by the 21st Century Frontiers Brain Research Center Program (H.K.). We thank Dr. Melitta Schachner for Tenascin R and Tenascin C antibodies and Dr. Arturo AlvarezBuylla for helpful comments.

Correspondence should be addressed to Dr. Woong Sun, Department of Anatomy, Korea University College of Medicine, Anam-dong, Sungbuk-gu, Seoul 136-705, Korea. E-mail: woongsun@korea.ac.kr. DOI:10.1523/JNEUROSCI.3903-07.2007

Copyright $\odot 2007$ Society for Neuroscience $\quad$ 0270-6474/07/2714392-12\$15.00/0 maintain chain-like interactions during their migration through the RMS. Glial cells within the RMS establish a tube-like structure that physically and molecularly separates immature neuroblasts from surrounding brain regions during their directional migration (Anton et al., 2004; Giachino et al., 2005). On their arrival in the $\mathrm{OB}$, only a subset of immature neurons survive, whereas $\sim 30-50 \%$ of adult-produced neurons undergo PCD in the OB within 1-month after being generated (Biebl et al., 2000; Winner et al., 2002). After the period of PCD, the surviving neurons develop into olfactory granule cells or periglomeruli interneurons (Belluzzi et al., 2003; Carleton et al., 2003; Hack et al., 2005; Kohwi et al., 2005). Because the CNS regions involved in the production (SVZ), migration (RMS), and PCD (OB) of adultproduced neurons are anatomically separated, the control of $\mathrm{OB}$ neurogenesis may require complex regulatory systems that can integrate these spatially separable events.

Several factors are involved in the control of adult OB neurogenesis. Neuronal activity is one of the key factors influencing $\mathrm{OB}$ neurogenesis by promoting the survival of newly produced neurons. For instance, olfactory neuronal activity increases and olfactory deprivation decreases the number of surviving $\mathrm{OB}$ neurons (Corotto et al., 1994; Fiske and Brunjes, 2001; Petreanu and Alvarez-Buylla, 2002; Rochefort et al., 2002; Mandairon et al., 2003). Adult neurogenesis has been proposed to modulate olfac- 
tory function such as odorant discrimination and odor-related memory (Lledo et al., 2006). This suggestion is primarily based on the strong correlation between these two events (OB neurogenesis and olfactory function) in several genetic mutant models and during the natural aging process (Gheusi et al., 2000; Enwere et al., 2004); however, more direct evidence for this relationship has also been reported in an insect model (Scotto-Lomassese et al., 2003).

Recently, we reported that the PCD of adult-produced hippocampal neurons is mediated by the proapoptotic gene Bax (Sun et al., 2004). Here we show that the PCD of adult-produced $\mathrm{OB}$ neurons is also primarily dependent on Bax as there is a significant reduction in the number of dying cells in the Bax-KO OB (Shi et al., 2005). This information allowed us to evaluate the influence of PCD on the proliferation, migration, and differentiation of adult-produced $\mathrm{OB}$ neurons and to ask whether the absence of PCD and cell renewal in the $\mathrm{OB}$ affected olfactory function.

\section{Materials and Methods}

Animals. Heterozygous Bax-KO mice were maintained on a C57BL/6 background. Sibling animals were collected and individually genotyped by PCR as previously described (Sun et al., 2003). For BrdU labeling, mice were injected once intraperitoneally with a BrdU solution $(50 \mu \mathrm{g} / \mathrm{g}$ body weight) after which the animals were killed either 2-h or 4-weeks after the injection.

Histology. To identify cells dying by apoptosis, DNA fragmentation was visualized by the TUNEL method, as previously described (Sun et al., 2004). For immunohistochemical analysis, animals were perfused with $4 \%$ paraformaldehyde and the brains were postfixed in the same fixative for $24 \mathrm{~h}$. Brains were then cryoprotected in 30\% sucrose, sectioned serially $(40 \mu \mathrm{m})$ and subsequent immunostaining was performed by the free-floating method. For BrdU staining, sections were pretreated with $0.2 \mathrm{~N} \mathrm{HCl}$ for $1 \mathrm{~h}$ at $37^{\circ} \mathrm{C}$, washed with PBS, and blocked with $5 \%$ goat serum and $0.1 \%$ Triton X-100 in PBS for 30 min. Primary antibodies [anti-BrdU, 1:10,000; anti-activated caspase-3 (Cell Signaling Technology, Beverly, MA), 1:200; anti-DCX (Santa Cruz Biotechnology, Santa Cruz, CA), 1:1000; anti-PSA-NCAM (Chemicon, Temecula, CA), 1:500; anti-calretinin (Swant, Bellinzona, Switzerland), 1:1000; anti-NeuN (Calbiochem, La Jolla, CA), 1:10,000; anti-GFAP (Sigma, St. Louis, MO), 1:25,000; anti-calbindin (Sigma), 1:10,000; anti-mDab-1 (Chemicon), 1:1000; anti-Reelin (Chemicon), 1:1000; anti-Tenascin R, 1:5, antiTenascin C, 1:5, anti-CREB, anti-phosphorylated-CREB (Cell Signaling Technology), 1:500; GABA (Sigma), 1:500] were applied overnight. After several washes with PBS, appropriate secondary antibodies were applied for $30 \mathrm{~min}$. Subsequently, sections were washed, mounted and observed with a fluorescence or confocal microscope (LSM510; Zeiss, Goettingen, Germany).

To quantify the number of labeled cells, sections were visualized under $40 \times$ magnification using a Zeiss AxioskopII microscope or a confocal microscope, and the images were captured using a computerized image program. All labeled cells in sections containing the SVZ (medial and mediolateral regions of the lateral ventricle in $0.5-1 \mathrm{~mm}$ bregma) and RMS (2.6-2.8 $\mathrm{mm}$ bregma) were counted. In the OB, immunolabeled cells were counted in microscope fields $(200 \times)$ from sections of the granule cell layer (GCL) (4.0-4.3 bregma). For the above-mentioned areas, two sections per area per animal $(n=4)$ were examined, and all the sections were carefully matched anatomically between animals. To assess the area of the OB granule cell layer (GCL), OBs were sectioned (12 $\mu \mathrm{m})$ serially, and stained with cresyl violet. The area of the GCL was measured by NIH Image software in every sixth section. Because the subependymal layer (SE) was not clearly distinguishable from the GCL in some sections, we included the SE in the measurements.

SVZ explant culture. Brains from $\mathrm{P} 4$ wild-type and Bax-KO mice were immersed in ice-cold artificial CSF (aCSF) containing (in mM): $\mathrm{NaCl}$ $125, \mathrm{KCl} 5, \mathrm{NaH}_{2} \mathrm{PO}_{4} 1.25, \mathrm{NaHCO}_{3} 26$, dextrose $10, \mathrm{CaCl}_{2} 2.5$, and $\mathrm{MgSO}_{4} 1$, equilibrated with $95 \% \mathrm{O}_{2} / 5 \% \mathrm{CO}_{2}$. Brains were cut in 300 - $\mu$ m-thick sections with a vibratome (Technical Products International) and the SVZa from the lateral wall of the anterior horn of the lateral ventricle was dissected and cut into small pieces (100-300 $\mu \mathrm{m}$ in diameter). The explants were embedded in 75\% Matrigel (BD Biosciences, San Jose, CA). After polymerization of Matrigel at $37^{\circ} \mathrm{C}$ for $10 \mathrm{~min}$, neurobasal medium containing B27 supplement, L-glutamine $(0.5 \mathrm{~mm})$, glutamic acid $(25 \mu \mathrm{M})$ and penicillin-streptomycin (1:1000) was added. Cultures were maintained in a humidified incubator at $5 \% \mathrm{CO}_{2}$ and $37^{\circ} \mathrm{C}$. After $72 \mathrm{~h}$ the explants were fixed with $4 \%$ paraformaldehyde and the nuclei of explants were stained with Hoescht33258 (1:1000) for $1 \mathrm{~h}$. For measurements of migration distance, images of explants were collected (Axiovert 200; Zeiss), and the distance between the border of the furthest cell migration and the edge of the explant was measured. Explants from 4 different animals were analyzed (14 individual WT and 6 Bax-KO explants) (Nguyen-Ba-Charvet et al., 2004).

For adult explant culture, SVZ explants were prepared from $300-\mu \mathrm{m}-$ thick sections. Typically $20-30$ explants were obtained per animal and 5-10 explants were plated in a $35 \mathrm{~mm}$ plastic dishes precoated with laminin $(5 \mathrm{mg} / \mathrm{ml})$. Explants were maintained in the medium containing $500 \mathrm{ml}$ of DMEM with $10 \%$ FBS. After $24 \mathrm{~h} 200 \mathrm{ml}$ of media was added, and the media was replaced every second day. Cultures were maintained in a humidified incubator at $5 \% \mathrm{CO}_{2}$ and $37^{\circ} \mathrm{C}$. After $5 \mathrm{~d}$ the explants were fixed with $4 \%$ paraformaldehyde and double-immunofluorescence labeling of GFAP and TuJ1 (1:500; Sigma) was performed. Immunolabeling was observed under a confocal microscope (Zeiss).

SVZ grafts. The EGFP ORF fragment was cloned into pCL retroviral vector (EGFP-CL). pCL was made by BglII/SspI fragment of pLNCX2 (Clontech, Mountain View, CA) and SspI/BamHI fragment of pDON-AI (TaKaRa, Otsu, Shiga, Japan) vectors. EGFP-CL was transfected into 293gpg packaging cells (Lipofectamine; Invitrogen) and supernatant containing viral particles (VSV-G pseudotyped recombinant retrovirus) was harvested at 3-10 d after transfection and centrifuged at 50,000 $\times \mathrm{g}$ in a Beckman SW28 rotor (Beckman Instruments, Palo Alto, CA) for $2 \mathrm{~h}$ at $4^{\circ} \mathrm{C}$. The pellet was resuspended in $1 / 200$ of the original volume of PBS. Viral titer was adjusted to $1 \times 10^{9} \mathrm{particles} / \mathrm{ml}$. The virus solution $(1.5$ $\mu \mathrm{l})$ was delivered to the SVZ of WT and Bax-KO postnatal day 4 (P4) pups through stereotaxic surgery (AP: 1, ML: 1, DV: 2). After $24 \mathrm{~h}$, the SVZ was dissected and minced into $\sim 60 \mu \mathrm{m}$ explants in DMEM (Cambrex Bioscience, Rockland, ME). SVZ cells were grafted bilaterally into the posterior RMS (AP: 2.4, ML: 1.2, DV: 4) of 4-month-old WT mice or the SVZ (AP: 1, ML: 1, DV: 2) of 12-month old Bax-KO mice (Lois and Alvarez-Buylla, 1994; Kirschenbaum et al., 1999). Conversely, Bax-KO cells were grafted into WT brain. Three weeks after grafting, animals were perfused with fixative as above.

Electron microscopy. Animals 2 months of age were deeply anesthetized with ketamine/xylazine and perfused intracardially with $100 \mathrm{ml}$ of freshly made $2 \%$ glutaraldehyde, $2 \%$ paraformaldehyde in $0.13 \mathrm{M}$ sodium cacodyalte buffer, $\mathrm{pH}$ 7.4, at a flow rate of $10 \mathrm{ml} / \mathrm{min}$. Perfused animals were kept at $4^{\circ} \mathrm{C}$ for $1-3 \mathrm{~h}$, then brains were carefully removed and placed in fixative overnight at $4^{\circ} \mathrm{C}$. Areas of interest were dissected using epiillumination from $200 \mu \mathrm{m}$ thick serial vibratome sections. Specimens were then embedded in Araldite 502 using a Lynx processor. One micron sections and subsequent $700 \AA$ thin sections were cut using an LKBWallac (Gaithersburg, MD) ultramicrotome, counterstained with toluidine blue for $1 \mu \mathrm{m}$ sections, or uranyl acetate in $100 \%$ methanol and subsequently lead citrate for thin sections, which were viewed with a Zeiss EM 10 electron microscope. To quantify the size of the RMS, the area was measured from toluidine blue stained $1 \mu \mathrm{m}$ sections using Scion (Frederick, MD) Image. The areas were then compared using GraphPad Software (San Diego, CA) Instat via an unpaired $t$ test to derive a two-tail P value. The number of astrocytes (B-cells) (Alvarez-Buylla and Lim, 2004) was then counted from the total RMS of adjacent thin sections.

Behavioral tests. For olfactory memory tests, a cinnamon-paprika odorant pair was used. After adaptation to the test cage $(45 \times 30 \mathrm{~cm})$ and to two small circular cups ( $3.5 \mathrm{~cm}$ diameter), mice were exposed to water for $5 \mathrm{~min}$. After $1 \mathrm{~h}$ retention intervals, mice were then exposed to water and a novel odor A (cinnamon), and the time spent investigating each odor was recorded for a maximum of $3 \mathrm{~min}$. After $3 \mathrm{~h}$, the watercinnamon pairing was presented again for short-term odorant memory. 
The next day ( $24 \mathrm{~h})$, mice were exposed to odor A (cinnamon) and a novel odor B (paprika) as a test for long-term odorant memory. Investigative scoring included orientation toward the dish when the animal's nose was within $1-2 \mathrm{~cm}$ of the dish.

To evaluate fine odor discrimination, mice were subjected to a mixed odor discrimination task using a taste-aversion paradigm (Enwere et al., 2004). After water deprivation for $24-\mathrm{h}$, mice were given 5 pretraining trials with water-vanilla pairing $[+]$. In this session, $12 \mu \mathrm{l}$ of water was placed in a sterile $35 \times 10 \mathrm{~mm}$ tissue culture dish, and $1 \mu$ l of vanilla extract (VAN) was applied to the surface of the water. Next, the mice were exposed to 5 consecutive trials of bitter ( $1 \%$ solution of denatonium benzoate; Sigma)coconut (COC) pairing [-]. For the discrimination test, mice were given two dishes, one of which contained water-VAN $[+]$, whereas the other contained bitter-COC $[-]$. They were tested for 10-trials per concentration of odor mixture with randomly altered dish positions and the percentage of correct discriminations was scored. In each trial; a 2-min time limit was used and if the mice drank water from the $[+]$ dish only, it was considered as a correct discrimination. The following conditions were considered to be errors: (1) if the mice chose the $[-]$ rather than the $[+] ;(2)$ if the mice chose the $[+]$ but within $30 \mathrm{~s}$ of that selection went on to select the [-]; and (3) if the mice made no selection in the 2 min time limit.

Statistical analysis. Statistical significance of the experiments was evaluated by 2-tailed ( $\alpha=$ 0.05 ) repeated-measures ANOVA (OB size, migrated cell number of the SVZ explant) and independent sample $t$ test (other experiments). All the analyses were performed with SPSS (Chicago, IL) software, and all values are given as mean \pm SEM.

\section{Results}

Reduction of programmed cell death of migrating neuroblasts and olfactory interneurons in Bax-KO mice

To examine whether the PCD of neurons/ neuroblasts in the SVZ, RMS and OB was affected by Bax-deletion, we quantified the number of TUNEL ${ }^{+}$ cells in these anatomical regions in WT and Bax-KO mice (Fig. 1). In 2-month old WT mice, TUNEL ${ }^{+}$cells were readily observed in the olfactory granule cell layer (OGL) of the OB and in the RMS and SVZ, whereas Bax-KO mice exhibited markedly reduced numbers of TUNEL ${ }^{+}$cells in all three anatomical regions (Fig. 1I). Among the three regions examined, PCD in the OGL was the most affected ( $<10 \%$ of WT values) by Bax deletion.

To further assess dying neurons in Bax-KO mice, we performed double immunofluorescence labeling for activated caspase- 3 and the postmitotic neuronal marker, NeuN (Fig. $1 G, H)$. In WT mice, caspase $-3^{+} / \mathrm{NeuN}^{+}$cells were detectable in the OB. In contrast, although we detected a few activated caspase $-3^{+}$cells in the Bax-KO OB, we failed to identify any NeuN ${ }^{+} /$caspase $-3^{+}$cells after a thorough examination of $16 \mathrm{OB}$ sections from 4 independent mice, indicating that there is virtually no death of differentiated postmitotic $\mathrm{OB}$ neurons in Bax-KO mice.
SVZ RMS

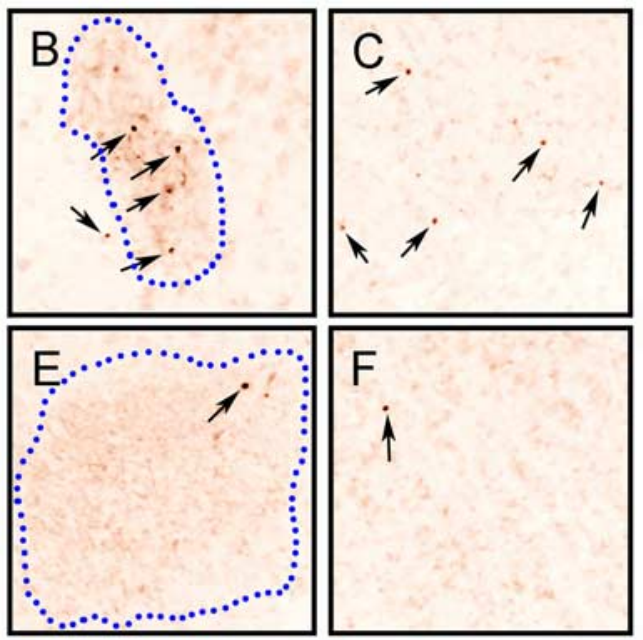

I

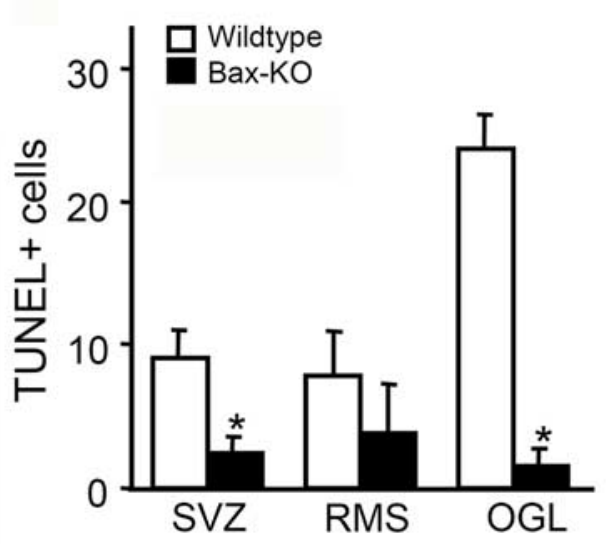

Figure 1. $P C D$ is reduced in the olfactory system of adult Bax-KO mice. Dying cells visualized by TUNEL in the SVZ $(A, D)$, RMS $(\boldsymbol{B}, \boldsymbol{E})$, and $\mathrm{OB}(\boldsymbol{C}, \boldsymbol{F})$ of WT $(\boldsymbol{A}-\boldsymbol{C})$ and Bax-KO $(\boldsymbol{D}-\boldsymbol{F})$ mice. Arrows indicate TUNEL ${ }^{+}$cells, and blue dotted lines in $\boldsymbol{B}$ and $\boldsymbol{E}$ indicate the margins of the RMS. LV, Lateral ventricle. $G, H$, Double-immunofluorescence labeling of $0 B$ with activated caspase-3 (red) and whereas caspase ${ }^{+}$cells lack NeuN-IR in Bax-KO $(\boldsymbol{H}) . \boldsymbol{I}$, Quantification of TUNEL ${ }^{+}$cells in SVZ, RMS, and olfactory granule cell layers (OGL) of WT and Bax-KO mice. Mean $\pm \mathrm{SEM}, n=4 .{ }^{*} p<0.05$, Student's $t$ test.

The number of proliferating neuroblasts and the size of the $\mathrm{OB}$ are normal in Bax-KO mice

Because the reduction of PCD in the OB may influence the production of neuroblasts by reducing neurogenesis in the SVZ, we compared the number of proliferating cells in 2-month-old WT and Bax-KO mice (Fig. 2). Quantification of the number of cells expressing a marker for proliferating cells, PCNA, failed to reveal a statistically significant difference in the numbers of $\mathrm{PCNA}^{+}$ cells between WT and Bax-KO mice in the SVZ, RMS or OB (Fig. $2 A-G)$. Similarly, there was no significant difference in the number of BrdU ${ }^{+}$cells between WT and Bax-KO mice in the SVZ or RMS after $2 \mathrm{~h}$ survival after a single BrdU injection (data not shown). We also observed that the proliferation rate was not significantly modified in 12-month-old Bax-KO mice compared with WT littermates (supplemental Fig. S1, available at www.jneurosci.org as supplemental material) (SVZ: $t_{(6)}=2.195, p=$ 0.071 , RMS: $\left.t_{(6)}=0.812, p=0.448\right)$. These results suggest that Bax-deletion and the resulting prevention of PCD does not influence the production of new neurons in the SVZ, consistent with 

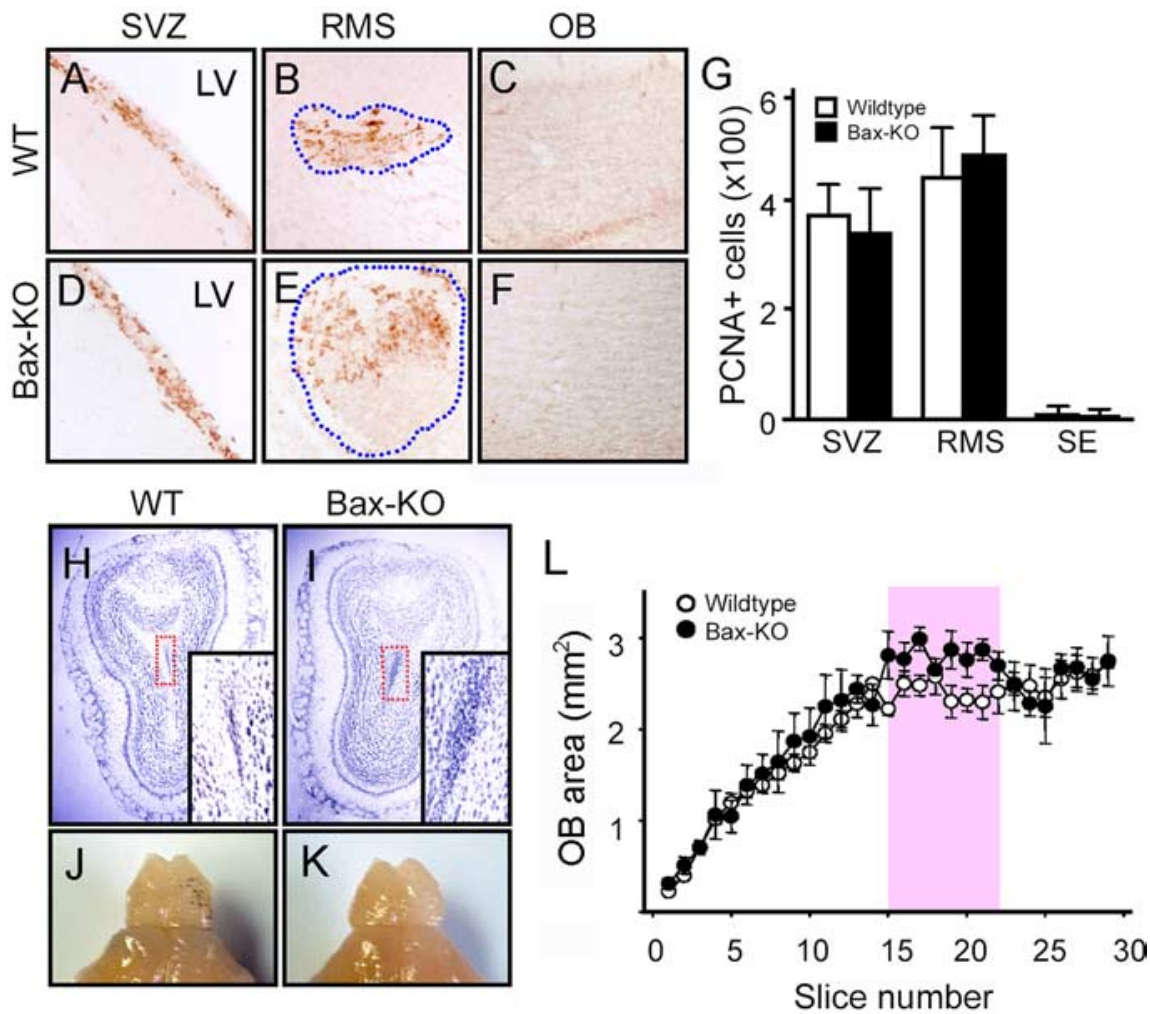

Figure 2. The distribution of proliferating ( $\left(\mathrm{PCNA}{ }^{+}\right)$neuroblasts in the adult olfactory system. $\boldsymbol{A}-\boldsymbol{F}$, Proliferating neuroblasts were visualized by PCNA labeling in the SVZ $(\boldsymbol{A}, \boldsymbol{D}), \operatorname{RMS}(\boldsymbol{B}, \boldsymbol{E})$, and $\mathrm{OB}(\boldsymbol{C}, \boldsymbol{F})$ of 2-month-old WT $(\boldsymbol{A}-\boldsymbol{C})$ and Bax-KO $(\boldsymbol{D}-\boldsymbol{F})$ mice. $\boldsymbol{G}$, Quantification of PCNA ${ }^{+}$cells. Mean \pm SEM, $n=4$. $\boldsymbol{H}-\boldsymbol{K}$, Nissl-stained coronal sections of WT $(\boldsymbol{H})$ and Bax-KO $(\boldsymbol{I})$ OB exhibit similar histology, except for a significant accumulation of cells in the subependyma (SE; insets show higher magnification of boxed area). The overall size of the $\mathrm{OB}$ was also comparable in WT $(\boldsymbol{J})$ and Bax-KO $(K)$ mice. $L$, Measurement of OGL area in serially cut sections. Note that the red shaded region exhibits an apparent increase, which is likely attributable to the expansion of the SE. $\mathrm{LV}$, Lateral ventricle.

our previous observations of adult neurogenesis and PCD in the dentate gyrus (DG) of Bax-KO mice (Sun et al., 2004).

Despite the striking reduction in PCD in the face of a normal production of new neurons, the size of the OB in 2-month-old Bax-KO mice, surprisingly, was similar to that of WT littermates (Fig. $2 H-L)\left(F_{(1,6)}=1291.65, p=0.203\right)$. However, we did observe that Bax-KO mice have an enlarged subependymal (SE) region which is the anterior continuum of the RMS. Consistent with the enlargement of the SE (insets in Fig. $2 H$ vs $I$ ) in the Bax-KO, the size of the OB area containing the SE was slightly increased (Fig. $2 C$, shaded in red).

Accumulation of ectopic neurons in the RMS of Bax-KO mice Whereas the size of the OB was normal, 2-month-old Bax-KO mice exhibited a substantial enlargement of the SVZ and RMS, which is attributable to the accumulation of $\mathrm{DCX}^{+}$cells (Fig. $3 A-E)$. The accumulation of cells in these regions appeared to continue into adulthood, such that these regions were markedly increased in 12 month-old Bax-KO mice compared with 2-month old animals (Fig. 3E) (supplemental Fig. S2, available at www.jneurosci.org as supplemental material) (2 M RMS: $t_{(6)}=$ 7.103, $p<0.005,12$ M RMS: $t_{(6)}=13.577, p<0.001,2$ M SVZ: $\left.t_{(6)}=15.941, p<0.0001,12 \mathrm{M} \mathrm{SVZ:} t_{(6)}=3.873, p<0.05\right)$. Furthermore, a subset of $\mathrm{DCX}^{+}$cells in 12-month-old Bax-KO mice appeared to be ectopically located in the ventral region of the lateral ventricle (supplemental Fig. S2, available at www.jneurosci.org as supplemental material). In parasagittal sections of DCX-immunoreactivity (IR) in the RMS of Bax-KO, a subset of
DCX-IR cells exhibited radially projecting processes (Fig. 3D, inset). Because normally migrating neuroblasts in the RMS exhibit a bipolar shape and have processes oriented tangentially, the aberrant projecting $\mathrm{DCX}^{+}$cells in Bax-KO mice do not appear to be migrating toward the OB. To examine this possibility, we injected BrdU into postnatal day 4 (P4), 2-month or 11month-old Bax-KO and WT mice and examined the distribution of $\mathrm{BrdU}^{+}$cells 1-month after BrdU injection (Fig. 3F-T). Because most newly produced neuroblasts can migrate into the $\mathrm{OB}$ within 1-month, only a few BrdU ${ }^{+}$cells were found in the SVZ or RMS in all WT age groups. In contrast, numerous $\mathrm{BrdU}^{+}$cells were localized in the SVZ and RMS in Bax-KO mice, indicating that a subset of Bax-KO neuroblasts failed to migrate into the $\mathrm{OB}$ (Fig. $3 R, S)\left(\mathrm{SVZ} ; 1 \mathrm{M}: t_{(6)}=5.332, p<0.005,3\right.$ $\mathrm{M}: t_{(6)}=6.449, p<0.001,12 \mathrm{M} t_{(6)}=$ 12.87, $p<0.0001$, RMS; $1 \mathrm{M}: t_{(6)}=11.71$, $p<0.001,3 \mathrm{M}: t_{(6)}=13.385, p<0.0001$, $\left.12 \mathrm{M}: t_{(6)}=0.269, p<0.0001\right)$. Interestingly, a greater proportion of newly produced $\mathrm{BrdU}^{+}$cells appeared to accumulate in the SVZ of old (12-month) vs young (3month) Bax-KO mice, suggesting that over time newly produced cells may accumulate between the OB and the SVZ. Accordingly, there was a progressive reduction in the number of newly produced $\mathrm{BrdU}^{+}$cells in the OGL of the OB in Bax-KO mice. There were significantly more P4-labeled $\mathrm{BrdU}^{+}$ cells in the OGL of Bax-KO vs WT littermates, whereas similar numbers of BrdU ${ }^{+}$cells were observed in 3-month old WT and Bax-KO. By 12-months, only a few BrdU ${ }^{+}$cells were observed in the Bax-KO OGL, whereas there were substantial numbers of $\mathrm{BrdU}^{+}$cells in WT littermates (Fig. 3T) $\left(1 \mathrm{M}: t_{(6)}=2.635, p<\right.$ $\left.0.05,3 \mathrm{M}: t_{(6)}=0.24, p=0.81,12 \mathrm{M}: t_{(6)}=17.07, p<0.001\right)$.

Differentiation of a subset of neuroblasts in the Bax-KO RMS We next examined the differentiation of cells in the RMS. Immunostaining for NeuN (an early differentiated neuronal marker) together with BrdU revealed that the majority of $\mathrm{BrdU}^{+}$ectopic cells in the Bax-KO RMS expressed this neuronal marker, whereas $\mathrm{NeuN}^{+}$cells were absent in the WT RMS. A Z-stack examination of $\mathrm{NeuN}^{+} / \mathrm{BrdU}^{+}$cells clearly demonstrated that a subset of $\mathrm{BrdU}^{+}$cells exhibited NeuN-IR (Fig. $4 B$, inset). Normally, a majority of RMS neuroblasts migrate to the $\mathrm{OB}$ in which they differentiate as calretinin ${ }^{+}$, $\mathrm{GABA}^{+}$cells in the OGL and a small subset (1-5\%) differentiate into $\mathrm{TH}^{+}$cells (Hack et al., 2005; Parrish-Aungst et al., 2007). Within the Bax-KO RMS, we observed an accumulation of calretinin $^{+}$and $\mathrm{GABA}^{+}$cells (Fig. $4 \mathrm{D}$ vs F), indicating that they had attained a differentiated OGL neuronal-like phenotype but in an ectopic position within the RMS. In contrast, although none of these ectopically localized cells expressed TH-IR (data not shown), some $\mathrm{TH}^{+}$cells were ectopically located in the Bax-KO OGL, whereas $\mathrm{TH}^{+}$cells were not found in the OGL of WT mice (Fig. 4G,H).

Recently, it has been reported that the phosphorylation of 
CREB is an early event involved in the differentiation and initial migration of neuroblasts (Giachino et al., 2005). Consistent with this report, we found that in WT mice the phosphorylation of CREB was greatly increased in the RMS proximal to the $\mathrm{OB}$ in which neuronal differentiation and the termination of RMS migration occurs (Fig. 4I,J). However, in the Bax-KO, CREB phosphorylation was ubiquitously expressed along most of the migratory route (Fig. $4 K, L$ ), suggesting that the absence of PCD may trigger a molecular program required for both the exit of neuroblasts from the RMS migratory stream and terminal differentiation.

\section{The impairment of cell migration in}

Bax-KO mice is noncell autonomous

To assess whether the impairment of neuronal migration in $\mathrm{Bax}-\mathrm{KO}$ is cellautonomous, we isolated SVZ explants and examined the chain migration pattern in vitro (Fig. $5 A-E$ ). Isolated SVZ explants (P4) from WT mice embedded in 75\% Matrigel showed the typical chain migration of neuroblasts, consistent with previous reports (Nguyen-Ba-Charvet et al., 2004). Similarly, neuroblasts in the Bax-KO SVZ explants also exhibited a normal pattern of chain migration. Frequency-fractionation analyses of the distance of neuroblast migration in WT and Bax-KO explants clearly demonstrated normal migration of Bax-KO neuroblasts. Because it is possible that SVZ-derived neuroblasts in Bax-KO mice lose their migratory ability in advanced age, we also compared the migratory behavior of SVZ explants from 12month-old WT and Bax-KO mice. As previously reported (Lois and AlvarezBuylla, 1993), although explants at this age do not exhibit typical chain migration, a subset of neuronal cells migrate from the WT explants on a laminin-coated dish. Similarly, Bax-KO-derived SVZ explants exhibited neuronal migration, suggesting that 12-month-old Bax-KO neuroblasts maintain a migratory potential.

To further evaluate the apparent noncell autonomous nature of the migration defect of Bax-KO cells in vivo, WT or Bax-KO SVZ microexplants (P4) labeled by retrovirus-GFP were grafted into the posterior RMS of WT mice (Fig. $5 F-K$ ). Three weeks after transplantation, GFP-labeled WT and Bax-KO cells were only infrequently observed in the rostral region of RMS (Fig. $5 G, J$ ) and $\mathrm{OB}$ (Fig. $5 H, K$ ). In the OB, both WT and Bax-KO grafted cells exhibited dendritic processes which are a typical characteristic of immature granule cells. Although the small sample numbers (WT, $n=2$; Bax$\mathrm{KO}, n=1$ ) did not allow us to statistically compare the migration efficiency of WT vs Bax-KO explants, similar numbers of $\mathrm{GFP}^{+}$cells were found in both the RMS $(2.7$ cells/section, and 2.2 cells/section in WT, 6 sections/animal; 3.0 cells/section in
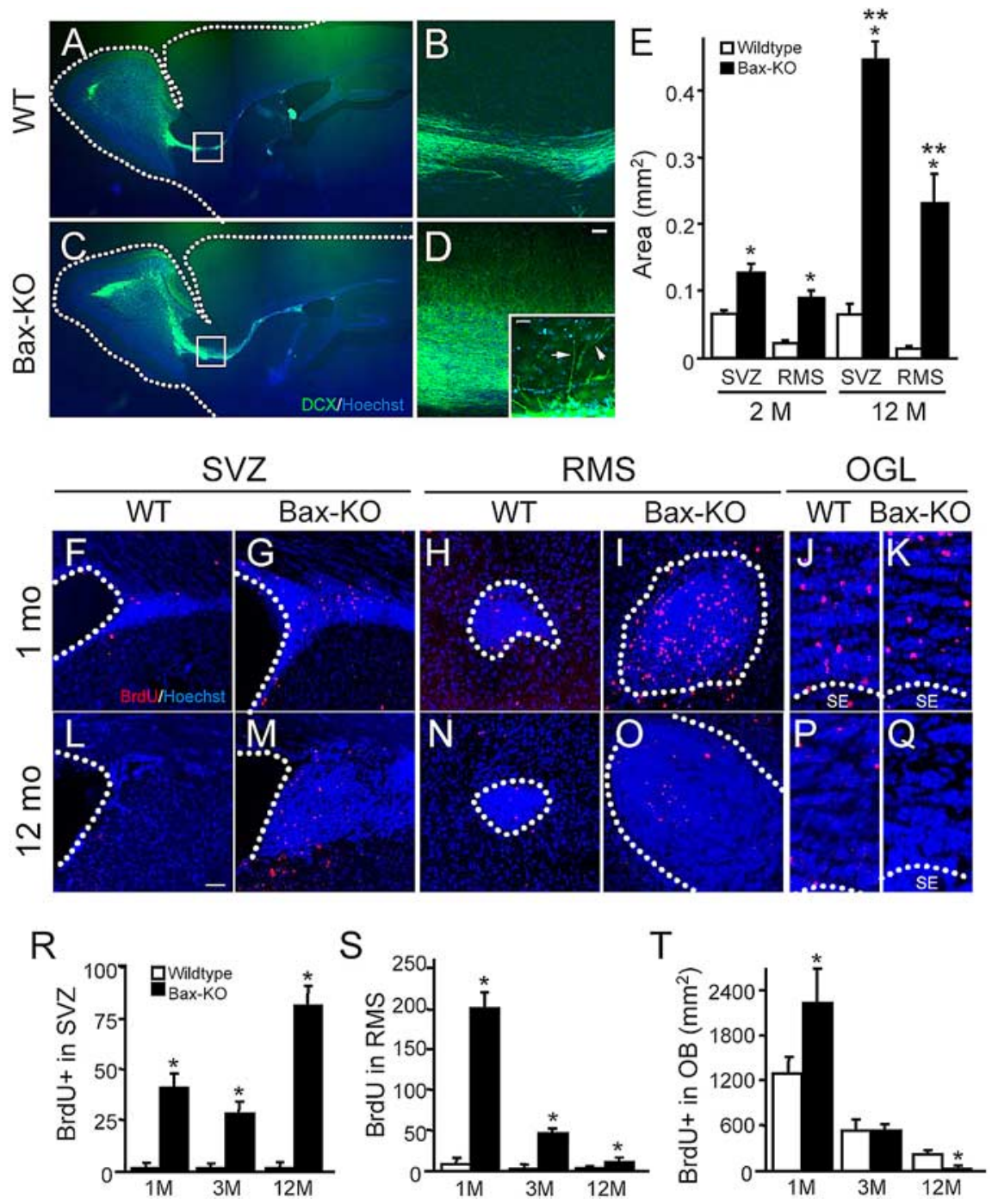

Figure 3. Impairment of RMS migration in Bax-KO mice. $\boldsymbol{A}-\boldsymbol{D}$, Parasagittal view of DCX-IR in 2-month-old WT $(\boldsymbol{A}, \boldsymbol{B})$ and Bax-KO $(\boldsymbol{C}, \boldsymbol{D})$ mice. $\boldsymbol{B}$ and $\boldsymbol{D}$ (and insets; scale bar, $20 \mu \mathrm{m})$ show higher-magnification views of boxed areas in $\boldsymbol{A}$ and $\boldsymbol{C}$ of sections are indicated by dashed lines in $\boldsymbol{A}$ and $\boldsymbol{C}$. $\boldsymbol{E}$, Quantification of the area of the DCX ${ }^{+}$region in SVZ and RMS of 2- and 12-month-old animals. The area containing $D C X^{+}$cells in anatomically matched sagittal sections $(40 \mu \mathrm{m})$ was measured under objective lens. We excluded the area containing $D C X{ }^{+}$radial fibers in Bax-KO RMS in these measurements. Mean \pm SEM $n=4$. ${ }^{*} p<0.05$, Student's $t$ test comparisons between WT versus Bax-K0 mice; ${ }^{* *} p<0.05$, Student's $t$ test comparisons between 2-versus 12-month-old age group. $\boldsymbol{F}$ - $\mathbf{Q}$, Distribution of $\operatorname{BrdU}^{+}$cells in SVZ $(\boldsymbol{F}, \mathbf{G}, \boldsymbol{L}, \boldsymbol{M}), \operatorname{RMS}(\boldsymbol{H}, \boldsymbol{I}, \boldsymbol{N}, \mathbf{0})$, and $0 \mathrm{GL}(\boldsymbol{J}, \boldsymbol{K}$ $\boldsymbol{P}, \mathbf{Q})$ at 1 month $(\boldsymbol{F}-\boldsymbol{I})$ after a single injection of $\operatorname{BrdU}$ on $\mathrm{P} 4$ in WT $(\boldsymbol{F}, \boldsymbol{H}, \boldsymbol{J}, \boldsymbol{L}, \boldsymbol{N}, \boldsymbol{P})$ and $\operatorname{Bax}-\mathrm{KO}(\boldsymbol{G}, \boldsymbol{I}, \boldsymbol{K}, \boldsymbol{M}, \mathbf{O}, \mathbf{Q})$ mice; BrdU is labeled red, and the nucleus is labeled blue (Hoechst33342). Dotted lines indicate the boundary of the RMS and subependyma (SE). Scale bar, $50 \mu \mathrm{m} . \boldsymbol{R}-\boldsymbol{T}$, Quantification of BrdU ${ }^{+}$cells in SVZ $(\boldsymbol{R}), \operatorname{RMS}(\boldsymbol{S})$, and OGL $(\boldsymbol{T})$. For the SVZ and RMS, the tota number of BrdU ${ }^{+}$cells in anatomically matched sections was counted; for $0 \mathrm{GL}$, BrdU ${ }^{+}$cells per unit area are shown. Mean \pm SEM, $n=4 .{ }^{*} p<0.05$, Student's $t$ test.

Bax-KO RMS, 7 sections) and the OB (5.4 cells/section, and 5.5 cells/section in WT, 8 sections/animal; 5.8 cells/section in Bax-KO RMS, 10 sections). Accordingly, Bax-KO cells appear to migrate normally in a WT RMS environment. Conversely, grafted WT SVZ cells failed to migrate toward the RMS/OB in the 12-month-old Bax-KO environment. From these data, we conclude that the impairment of neuronal migration in Bax-KO mice observed in vivo is not attributable to cell-autonomous defects, but rather must involve the perturbation of signals from nonmigrating cells.

The impairment of the glial tube in the RMS of Bax-KO mice Next we examined whether there are alterations in signals that regulate neuronal migration such as Reelin, Tenascin R, and Slit 


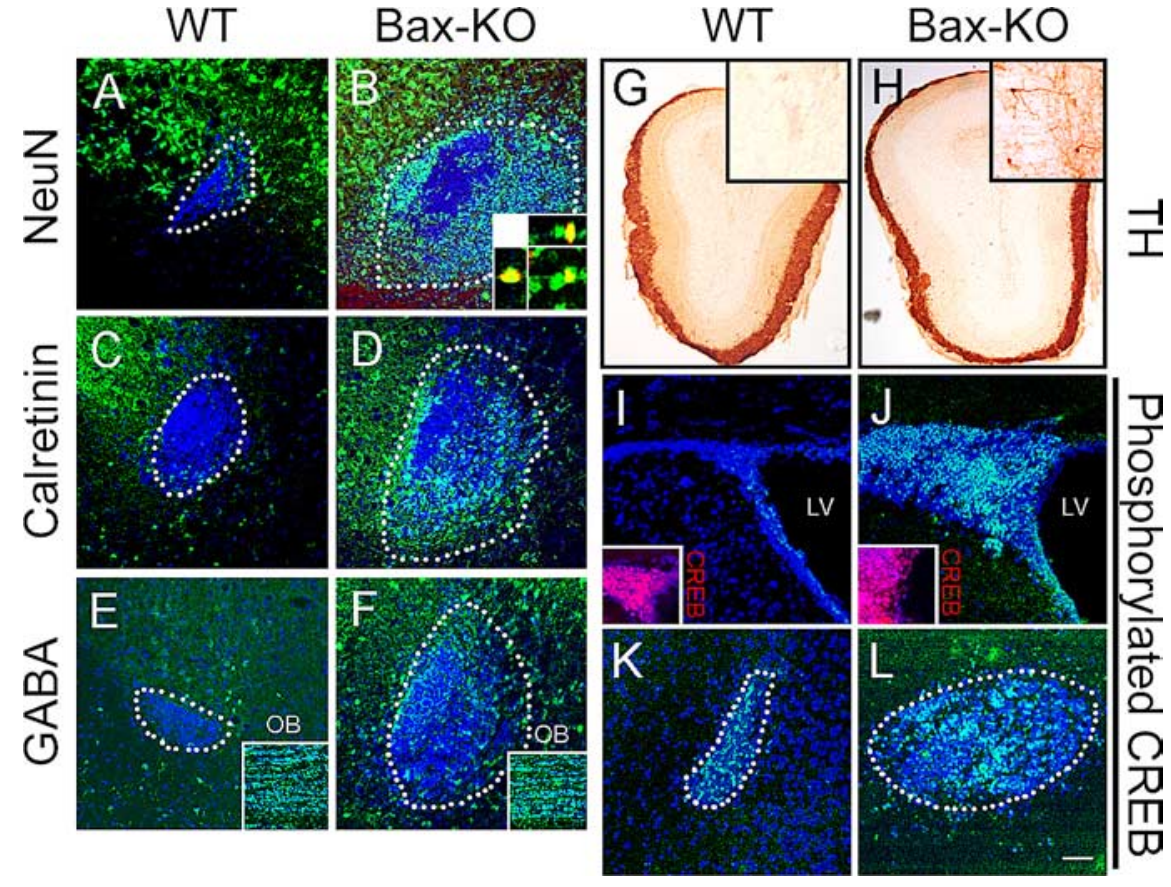

Figure 4. Differentiation of migration-impaired neuroblasts in Bax-KO RMS. $\boldsymbol{A}, \boldsymbol{B}$, Immunofluorescence staining for the mature granule cell marker NeuN (green) and BrdU (red) in WT $(\boldsymbol{A})$ and Bax-KO (B) RMS. Nuclei were counterstained with Hoechst33342 (blue). Dotted lines indicate the boundary of the RMS. Inset in $\boldsymbol{B}$ shows complete overlap (yellow) of NeuN-IR (green) and BrdU-IR (red) in Z-sectioned confocal images. C, D, Immunostaining of the mature granule cell marker calretinin (green) in WT $(\boldsymbol{C})$ and Bax-KO (D) RMS. $\boldsymbol{E}, \boldsymbol{F}$, Immunostaining of the interneuron marker GABA (green) in WT (E) and Bax-KO $(\boldsymbol{F})$ RMS; insets show GABA-IR in the OB. $\boldsymbol{G}, \boldsymbol{H}$, TH immunostaining in WT $(\boldsymbol{G})$ and Bax-KO $(\boldsymbol{H})$ OB; insets in $\boldsymbol{G}$ and $\boldsymbol{H}$ show a higher-magnification view of OGL. $\boldsymbol{I}-\boldsymbol{L}$, Phosphorylated CREB immunostaining (green) in SVZ $(\boldsymbol{I}, \boldsymbol{J})$ and RMS $(\boldsymbol{K}, \boldsymbol{L})$ of WT $(\boldsymbol{I}, \boldsymbol{K})$ and Bax-KO $(\boldsymbol{J}, \boldsymbol{L})$ mice; insets in $\boldsymbol{I}$ and $\boldsymbol{J}$ show pan-CREB immunostaining (red) in adjacent sections. Scale bar, $50 \mu \mathrm{m}$. LV, Lateral ventricle.

in Bax-KO mice. There are similar numbers of Reelin ${ }^{+}$mitral cells in the WT and Bax-KO OB and the expression of Tenascin R in the OGL was also normal in Bax-KO mice. In fact, we failed to find any substantial changes in the distribution or expression of any of these migratory signals in Bax-KO mice (supplemental Fig. S3, available at www.jneurosci.org as supplemental material).

In contrast to the apparent lack of a change in migratory signals, there was an impairment of RMS glial tube formation in Bax-KO mice. Although migrating neurons in the RMS do not directly make contact with glial cells (Law et al., 1999), postnatally formed glial tubes are known to serve as a barrier between immature migrating neuroblasts and surrounding CNS regions. Because the glial tube was eccentrically oriented in the Bax-KO RMS (Fig. 6), the RMS could be divided into two regions, depending on glial cell density: the A-zone (astrocyte-rich); and the $\mathrm{N}$-zone (neuron-rich, see below). The $\mathrm{N}$-zone in the Bax-KO was devoid of PSA-NCAM-IR, indicating that cells within the N-zone are not migrating neuroblasts but rather are ectopically differentiating neurons. Consistent with this idea, a majority of $\mathrm{N}$-zone cells also expressed the mature neuronal marker, MAP-2. A summary of the expression pattern of cell types in the two zones is presented in Figure 6O. Within the A-zone of the Bax-KO, glial cells appear to be more disorganized and the number of $\mathrm{GFAP}^{+}$ glial cells appears to be reduced compared with the WT RMS, although we did not quantitatively confirm this.

It is known that the outer margin of the RMS is established by extracellular matrix molecules such as Tenascin $\mathrm{C}(\mathrm{TN}-\mathrm{C})$ which separates neuroblasts from surrounding mature brain structures. Because the glial tube in Bax-KO is deformed and there is an eccentric accumulation of migrationdefective neurons in the RMS, we reasoned that the failure of efficient separation of neuroblasts in the A-zone from mature neurons in the $\mathrm{N}$-zone may be responsible for the impairment of migration in Bax-KO mice. The outer margins of the RMS were readily distinguishable by TN-C immunoreactivity in both WT and Bax-KO mice (Fig. 6I-N, inset). However, there was no apparent border between the A- and N-zones, suggesting that these two zones may not be separated physically and thus that interactions between migrating neuroblasts and ectopically differentiating neurons may occur.

The ultrastructure of the RMS in the Bax-KO mice

SVZ

The subventricular zone (SVZ) resides along the lateral ventricle from which it is separated by epithelial cells (e). It generates neuroblasts which migrate along a glial scaffolding via the rostral migratory stream (RMS) to the olfactory bulb (OB) (GarciaVerdugo et al., 1998; Alvarez-Buylla and Garcia-Verdugo, 2002). Migrating neuroblasts (A-cells) are generated from progenitor cells (C-cells), which are in turn generated from astrocyte-like cells (B1, B2 cells) (Doetsch, 2003; Alvarez-Buylla and Lim, 2004). The B cells have the ultrastructure (Peters et al., 1976) and immunohistochemical characteristics (Doetsch et al., 1997) of astrocytes. Based on previously published criteria (Doetsch et al., 1997), a comparison of this system in WT (Fig. 7A) vs Bax-KO mice (Fig. $7 B$ ) did not show any discernable differences, although we cannot rule out disturbances in the migratory chain orientation that might be detected using 3-D reconstruction of large regions of the SVZ. However, in the Bax-KO, at both the base of the ventricle and the roof just below the corpus callosum (Fig. 7C) there is an increased accumulation of migrating cells compared with WT (Fig. 7D), presumably attributable to their rescue from PCD.

\section{RMS}

In normal animals, groups of A cells migrate along B cells, which form a loosely knit scaffolding throughout the RMS (Lois et al., 1996; Peretto et al., 1997). However, as previously discussed above, this system appears to be disrupted in the Bax-KO. By careful mapping of the RMS at the EM level of Bax-KO and plotting the position of the various cell types, we confirmed our immunohistochemical observation that astrocytes are primarily found in the A-zone, with the $\mathrm{N}$-zone providing a cap around it toward the anterior olfactory nucleus; however, a few $\mathrm{N}$ cells could also be found scattered along the edge of the intrabulbar anterior commissure. Quantitation of the size of the RMS shows a highly significant increase in the Bax- $\mathrm{KO}\left(\mathrm{WT}=0.016 \mathrm{~mm}^{2} \pm\right.$ $0.006, n=7$; Bax-KO $\left.=0.107 \mathrm{~mm}^{2} \pm 0.056, n=6, p=0.0001\right)$. Semiquantitative analysis at the EM level of astrocyte-like B cells within the entire RMS from adjacent thin sections (3 animals/ group) indicate that Bax-KO has $\sim 40 \%$ fewer B cells than WT. Thus, as can be seen in Figure $8 A$, the WT RMS contains groups 
of A cells interspersed with B cells consistent with a previous report (Lois et al., 1996). The remnants of dying cells indicates normal cell death in WT mice (Figs. 7, $8)$, whereas in the Bax-KO RMS we saw no signs of cell death. In addition to A cells, a novel cell type was seen in the Bax-KO RMS that appeared neuron-like (N). Sparse B cells were primarily concentrated in the A-zone, whereas $\mathrm{N}$ cells (Fig. $8 \mathrm{~B}$, left of field) were located in a separate zone $(\mathrm{N})$. Ultrastructural differences in cell types are illustrated in Figure 8 in which $A^{\prime}$ and $B^{\prime}$ are enlargements of the boxed areas in $\mathrm{A}$ and $\mathrm{B}$, respectively. As can be seen in $A^{\prime}, \mathrm{B}$ cells contain light filamentous cytoplasm $\left(^{*}\right)$ and nuclei heavily rimmed with chromatin that is characteristic of astrocytes. The A cell in $B^{\prime}$ has a relatively small, dark nucleus with dense chromatin and scant, dark cytoplasm that is surrounded by extracellular spaces characteristic of migrating cells. The $\mathrm{N}$ cell, in contrast, has a large, light nucleus and lighter more developed cytoplasm containing mitochondria, ribosomes, and RER, but no filaments.

An interesting difference between WT and Bax-KO was observed in the distribution of glial end feet around blood vessels (del Zoppo and Hallenbeck, 2000). Many functions of astrocytes are related to their structural arrangement comprising the blood-brain barrier (Simard et al., 2003). Palmer et al. (2000) describe the occurrence of adult neurogenesis in the angiogenic niche of the subgranular zone of the hippocampus, implying a direct role for circulating factors in adult neurogenesis. In WT mice, these end feet $\left(^{*}\right)$ commonly ensheathed the blood vessels, as seen in Figure $8 G$, whereas very few such structures could be seen in Bax-KO, in which the vessels were primarily surrounded by neuropil and A cells (Fig. $8 \mathrm{H}$ ).

Puncta adherentia, which probably act to maintain cell-cell contacts (Peters et al., 1976), were common among cells throughout the RMS. In WT mice, groups of A cells (Fig. 8C) often had such puncta (arrows), frequently accompanied by the formation of coated vesicles $\left({ }^{*}\right)$. Contacts between $\mathrm{A}$ and $\mathrm{B}$ cells were also common (Fig. $8 \mathrm{D}$ ). In the Bax-KO, there were also puncta-like contacts between $\mathrm{A}$ and $\mathrm{N}$ cells (Fig. $8 \mathrm{E}$ ); $\mathrm{N}$ cells also exhibit synapse-like profiles (Fig. $8 E$, double arrows). N-N puncta adherentia are illustrated in Figure $8 F$ (arrows). Contacts were also seen between $\mathrm{B} / \mathrm{N}$ and $\mathrm{A} / \mathrm{N}$ cells.

\section{Bax-KO mice exhibit normal olfactory behavior}

To evaluate the function of the olfactory system in Bax-KO mice, we assessed olfactory discrimination and odorant memory which are thought to be related to adult neurogenesis (Gheusi et al., 2000; Mechawar et al., 2004). We found similar numbers of adult-produced $\mathrm{OB}$ neurons in 3-month-old Bax-KO mice and WT littermates (Fig. 3) and because PCD is absent or greatly reduced in Bax-KO mice, this age group offers a unique opportunity to evaluate olfactory function in the absence of PCD. To evaluate the ability to recognize and remember odors, odorants were presented by the procedure summarized in Figure $9 \mathrm{~A}$. Bax-KO mice appeared to recognize and distinguish familiar vs novel odors (cinnamon vs paprika) at both 3 and $24 \mathrm{~h}$ intervals (Fig. $9 B$ ) (3-h test: $t_{(15)}=1.091, p=0.293 ; 24$-h test: $t_{(15)}=0.066$, $p=0.949$ ). Similar results were obtained with simple odors (C3 vs $\mathrm{C6}$ ) which involve single populations of $\mathrm{OB}$ glomerulus circuits (data not shown; 3 -h test: $t_{(18)}=1.345, p=0.195 ; 24$-h test: $t_{(18)}=0.372, p=0.783$ ) (Mechawar et al., 2004). Next, we analyzed the olfactory function of 12-month old Bax-KO mice. By this age, neither the entry of new neurons into the OB nor PCD was observed in the Bax-KO. If the perturbation of OB cellular homeostasis plays a role in olfactory function, we reasoned that there should be substantial functional impairment in the BaxKO. However, 12-month old Bax-KO mice exhibited virtually normal behaviors (Fig. 9C) (3-h test: $t_{(11)}=0.318, p=0.756$; 24-h test: $\left.t_{(11)}=1.407, p=0.187\right)$.

Because the ability of fine olfactory discrimination is reported to be correlated with age and neurogenesis (Enwere et al., 2004), we also tested whether Bax-KO mice exhibit normal fine odor discrimination. In this task, mice were conditioned to VAN with distilled-water $[+]$ and to COC with bitter taste $[-]$. After conditioning, animals were exposed to the dishes containing two mixtures of VAN and COC of different concentrations. In the dish containing a higher concentration of COC, the bitter taste [-] was included. Over 10-trials per single mixture, the percent- 


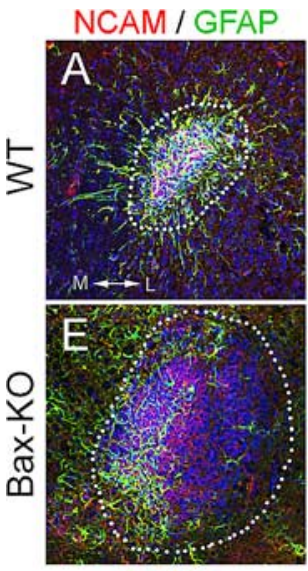

\section{DCX / GFAP}
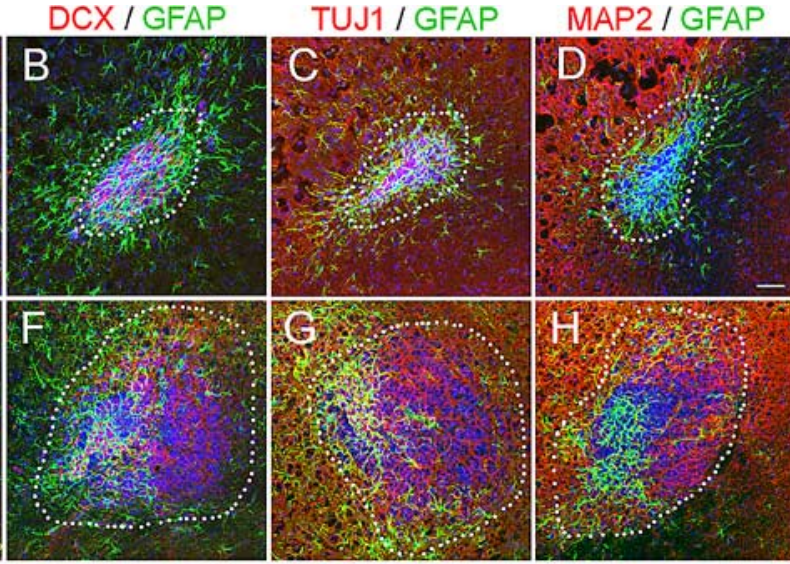

TN-C
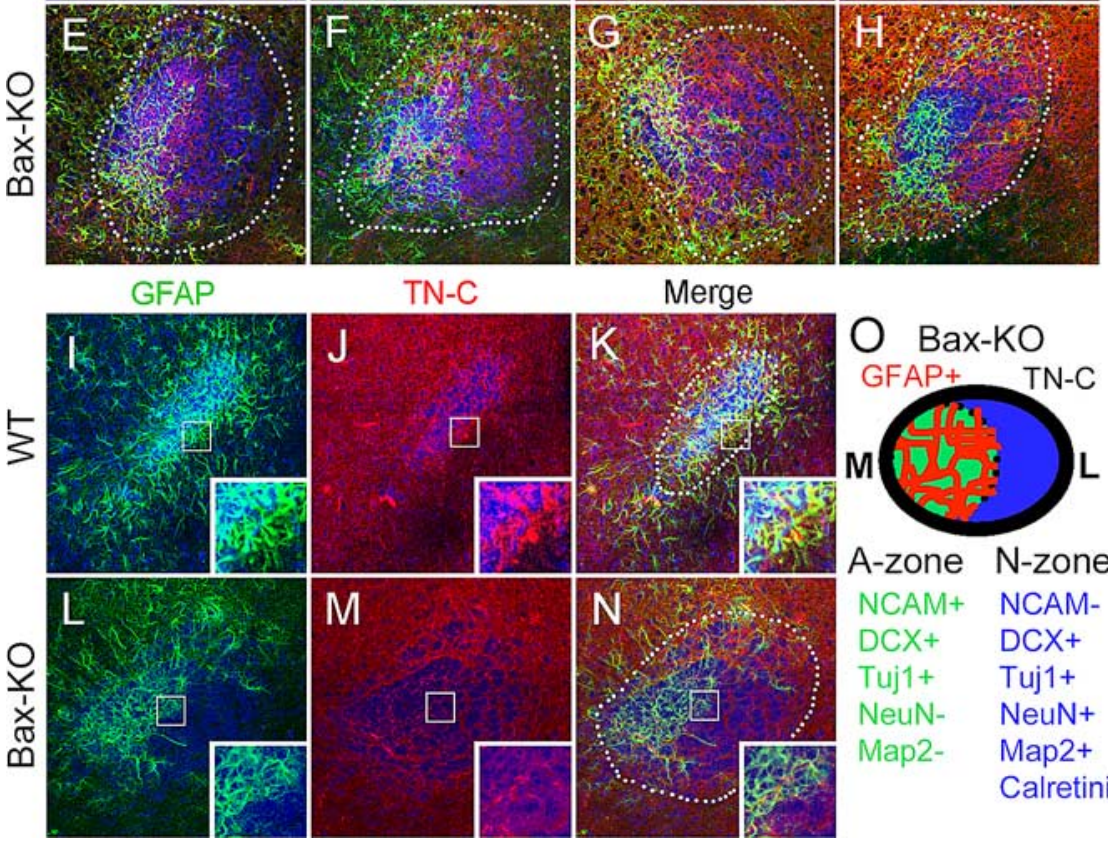

A-zone $\mathrm{N}$-zone

$\mathrm{NCAM}+\mathrm{NCAM}-$ $\mathrm{DCX}+\mathrm{DCX}+$ Tuj1+ Tuj1+ NeuN- NeuN+ Map2- Map2+ Calretinin+

Figure 6. Double-immunofluorescence labeling for NCAM/GFAP $(\boldsymbol{A}, \boldsymbol{E}), \operatorname{DCX} / \mathrm{GFAP}(\boldsymbol{B}, \boldsymbol{F}), \operatorname{TUJ}-1 / \mathrm{GFAP}(\boldsymbol{C}, \boldsymbol{G}), \operatorname{MAP} 2 / \operatorname{GFAP}(\boldsymbol{D}$, $\boldsymbol{H})$, and GFAP/Tenacin-C $(\boldsymbol{I}-\boldsymbol{N})$ in the RMS of 2-month-old WT $(\boldsymbol{A}-\boldsymbol{D}, \boldsymbol{I}-\boldsymbol{K})$ and Bax-KO $(\boldsymbol{E}-\boldsymbol{H}, \boldsymbol{L}-\boldsymbol{N})$ mice. Dotted lines indicate the boundary of the RMS. Insets in $\boldsymbol{I}-\boldsymbol{N}$ show higher-magnification images of the boxed areas. $\mathbf{0}$, Schematic summary of the distribution of immature and mature neuronal makers in the Bax-KO RMS. Within the RMS, there are two separate regions; one contains a glial tube $\left(\mathrm{GFAP}^{+}\right)$that is PSA-NCAM ${ }^{+}, \mathrm{DCX}^{+}, \mathrm{TUJ}_{-}{ }^{+}$, but is NeuN ${ }^{-}, \mathrm{MAP2}^{-}$(A-zone), whereas the N-zone is devoid of a glial tube and contains more mature neurons that were PSA-NCAM ${ }^{-}, \mathrm{NeuN}^{+}$and $\mathrm{MAP2}^{+}$.

age of correct choices was scored as previously described (for details, see Material and Methods). Although we found an agedependent decline in the ability to perform fine odor discriminations in WT mice (Enwere et al., 2004), we failed to detect any significant differences between WT and Bax-KO littermates at either 3- or 12-months of age (Fig. 9D,E) (3-M old group: (VAN: $\mathrm{COC}=100: 0) t_{(6)}=0.45, p=0.67$, (VAN:COC $\left.=58: 42\right) t_{(6)}=$ $0.21, p=0.84$, (VAN:COC $=56: 44) t_{(6)}=0.6, p=0.57 ; 12-\mathrm{M}$ old group: (VAN:COC $=100: 0) t_{(8)}=1.27, p=0.24$, (VAN: $\mathrm{COC}=65: 35) t_{(8)}=0.95, p=0.34$, (VAN:COC $\left.=60: 40\right) t_{(8)}=$ $0.632, p=0.55)$. Collectively, these data suggest that neither PCD nor cell turnover are required for odor discrimination or odor memory. Accordingly, other age-related changes may be responsible for the similar age-dependent impairment of these behaviors in both WT and Bax-KO mice.

\section{Discussion}

We have systematically evaluated the significance of PCD in the olfactory system on the proliferation, migration, differentiation and function of adult generated neurons. In the absence of PCD in the Bax-KO OB, we found that neuronal migration and differentiation were significantly affected, whereas proliferation of stem cells and olfactory function were relatively spared. We previously reported that the prevention of PCD of other neuronal populations in Bax-KO mice is compensated for by the alteration of other developmental events (Sun et al., 2003; Buss et al., 2006), and that this adaptation allows animals to develop with relatively normal behavioral function. In this respect, the limited neuronal migration in the absence of PCD observed here may serve as another biological strategy to maintain normal olfactory function when PCD is perturbed.

\section{The PCD of OB neurons is dependent on} the proapoptotic gene $\mathrm{Bax}$

In Bax-KO mice, PCD in the OB system is significantly reduced, although perhaps not completely absent. We failed to detect any $\mathrm{NeuN}^{+}$cells showing activated caspase-IR in the Bax-KO OB, suggesting that Baxdeletion may, in fact, completely eliminate the PCD of postmitotic, differentiated neurons in the OB. Consistent with this, we never observed signs of cell degeneration in our light or electron microscopic observations. Conversely, the PCD of mitotic neuroblasts is relatively spared in Bax- $\mathrm{KO}$ mice (White et al., 1998; Sun et al., 2003, 2004). The proapoptotic gene Bak is present in dividing neuroblasts but absent in postmitotic neurons (Lindsten et al., 2003). Bax/Bak double mutant mice have a more severe phenotype involving the rescue of dividing neuroblasts, and these mice have an increased accumulation of neuroblast in the RMS compared with Bax-KO mice (Lindsten et al., 2000, 2003). Thus Bak appears to be required for the PCD of precursor cells, whereas Bax is necessary for the PCD of postmitotic neurons.

\section{Proliferation is not affected by the absence of PCD}

Despite the marked reduction of PCD in the Bax-KO, the proliferation of neural stem cells in the SVZ/RMS was not substantially modified, suggesting that PCD and proliferation of stem cells are not directly linked. We also examined whether cell proliferation is perturbed in 12-month-old Bax-KO mice in which migration in the RMS is severely impaired; however, $\mathrm{PCNA}^{+}$cells in the Bax-KO SVZ were not significantly increased compared with WT littermates (supplemental Fig. S1, available at www.jneurosci.org as supplemental material). Previously, we found a similar dissociation between PCD and proliferation of progenitor cells in the DG of Bax-KO hippocampus (Sun et al., 2004). Independent control of PCD and stem cell proliferation has been previously proposed based on the observation that stem cell proliferation is normal after surgical removal of the OB (Kirschenbaum et al., 1999). However, in other reports, the removal of the OB was found to suppress the proliferation of SVZ stem cells (Jankovski et al., 1998; Keilhoff et al., 2006). Because the invasive surgical procedures used in all of these studies could affect the results, our observations in the Bax-KO mice may provide more reliable direct evidence that $\mathrm{PCD}$ does not affect the proliferation of stem/ progenitor cells. It has also been reported that increased neurogenesis in mCD24-deficient mice results in enhanced PCD of OB neurons such that the final number of adult-produced cells in the 
OB is comparable with normal values (Belvindrah et al., 2002). Therefore, it appears likely that PCD limits the final number of surviving neurons independent of proliferation and that there is no feedback loop to modulate the proliferation of new neurons by subsequent differential PCD.

Consistent with normal proliferation but the absence of PCD in Bax-KO mice, we observed an accumulation of cells in the RMS and SVZ. We estimated that an average $>10,000$ cells/d accumulate in the Bax-KO migratory track during 1-12 month period (supplemental Fig. S2, available at www.jneurosci.org as supplemental material). Although the estimated daily neuronal accumulation in Bax-KO mice appears to be less than the previously estimated number of newly produced $\mathrm{OB}$ cells per day ( $\sim 30,000$ cells; Alvarez-Buylla et al., 2001), we did not consider in our calculations the age-dependent reduction of adultgenerated $\mathrm{OB}$ cells or the presence of ectopically localized cells (e.g., the cell population in the ventral brain area). Accordingly, although we cannot completely exclude the possibility that a subset of excess Bax-KO neurons may undergo Bax-independent $\mathrm{PCD}$, it appears that a majority of excess Bax-KO neurons are continuously accumulating in the SVZ-RMS.

\section{The perturbation of RMS migration in Bax-KO mice}

Whereas excess neurons accumulated in the vicinity of the RMS in Bax-KO mice, the impairment of RMS migration does not appear to be attributable to a cell-autonomous defect of Bax-KO neuroblasts. A subset of neuroblasts was able to migrate into the $\mathrm{OB}$ in 1-3 month-old Bax-KO mice, and SVZ explants from Bax-KO mice exhibit normal chain migration in vitro. This raises the obvious question of what causes the defect in RMS migration in Bax-KO mice. First, we considered the possibility of changes in the expression of, or responsiveness to, chemoattractants. However, Bax-KO mice exhibited normal levels of known RMS chemoattractants and repellents such as Reelin, Tenascin-R, and Slits (Hu et al., 1996; Hack et al., 2002; Nguyen-Ba-Charvet et al., 2004; Saghatelyan et al., 2004). However, we can not exclude the possibility that other novel chemoattractants may be involved in the migration defects. Injury or local induction of apoptosis in non-neurogenic brain regions promotes the migration of adult produced neurons to the sites of injury (Magavi et al., 2000; Nakatomi et al., 2002), raising the possibility that neuronal death and migration are related. Dying cell themselves or neighboring cells such as phagocytic microglia might release chemoattractant signals (Agasse et al., 2004; Belmadani et al., 2006). Although it has been reported that surgical removal of the OB does not perturb migration in the RMS (Kirschenbaum et al., 1999), other less invasive approaches may be required to assess this issue.

Several of our observations suggest that the impairment of migration in the RMS of Bax-KO mice is related to perturbation of cell-cell interactions. First, we observed that a subset of cells in the vicinity of the RMS lose PSA-NCAM expression, a CAM which is known to be essential for the maintenance of chain formation of migrating neuroblasts (Hu et al., 1996); NCAM-KO mice have significantly reduced numbers of $\mathrm{OB}$ neurons, that is mainly attributable to impaired RMS migration (Chazal et al., 2000; Hack et al., 2002). Furthermore, enzymatic removal of PSA from NCAM blocks RMS migration and promotes premature differentiation of neuroblasts (Petridis et al., 2004), similar to our observations in the Bax-KO. We also observed defects in the development of the glial tube in the RMS of Bax-KO mice. The glial tube was eccentrically formed and the tube-like arrangement appeared to be disrupted. Ultrastructurally, we found many free neuroblasts (A-cells) in the Bax-KO RMS, whereas most neuro-

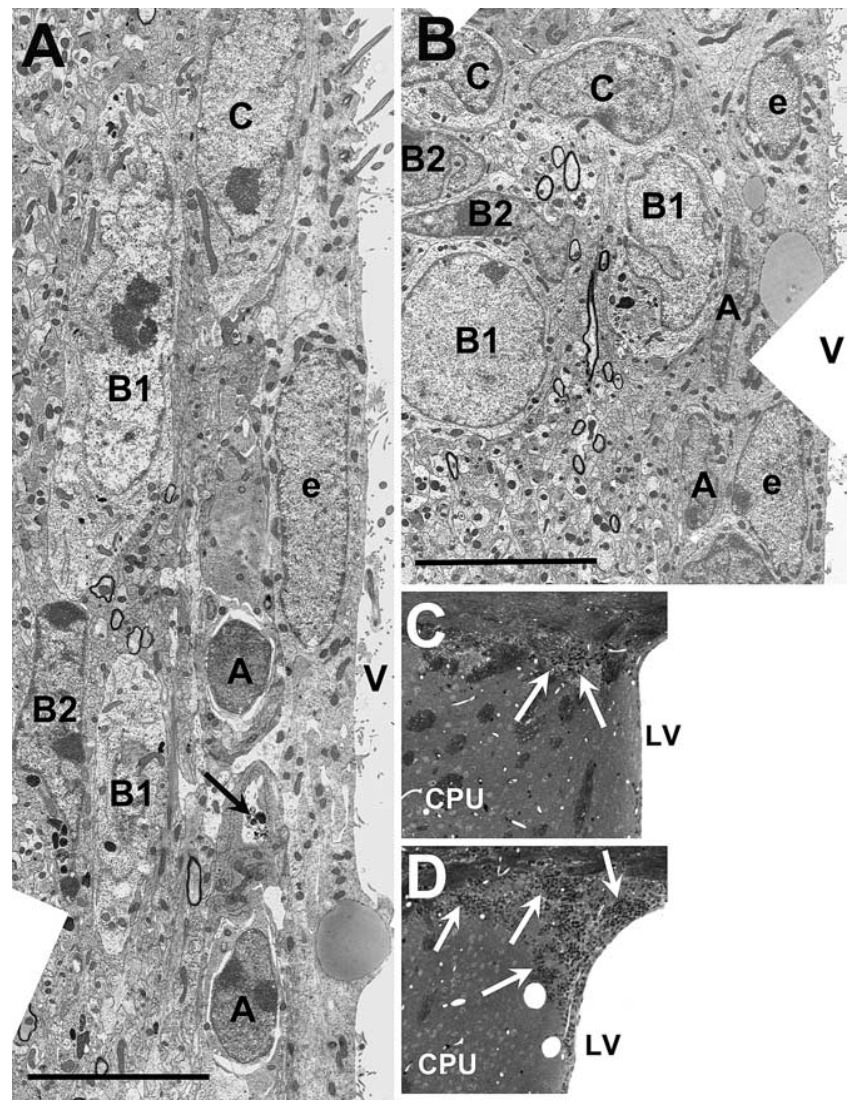

Figure 7. The SVZ of both 2-month-old WT $(\boldsymbol{A})$ and Bax-KO $(\boldsymbol{B})$ mice exhibit a typical arrangement of niche components. A, Migrating neuroblast; B1, B2, astrocytes; $C$, precursor cell; e, ependymal cell; V, lateral ventricle. Scale bar, $10 \mu \mathrm{m}$. Arrow indicates cellular debris from normally occurring cell death. Cells were classified according to criteria established by Doetsch et al. (1997). C, The roof of the lateral ventricle immediately below the corpus callosum shows few neuroblasts migrating toward the RMS in the WT compared with the Bax-KO in which large numbers of cells are found ( $\boldsymbol{D}$, arrows); this accumulation also occurs at the base of the ventricle (data not shown). CPU, Caudate-putamen; LV, lateral ventricle.

blasts (A-cell clusters) are surrounded by glial cells (B-cells) in WT mice. The glial tube has been proposed to function as a physical and molecular barrier for proper RMS migration, by preventing direct physical contacts between neuroblasts and surrounding brain structures, and by sequestering migrationinhibitory factors such as GABA (Bolteus and Bordey, 2004). The role of the glial tube for normal migration in the RMS is also consistent with the observation that selective loss of ErbB4 in $\mathrm{GFAP}^{+}$cells results in disruption of the glial tube and impairment of RMS migration (Anton et al., 2004). Accordingly, disruption of the glial tube and the accumulation of $\mathrm{GABA}^{+}$cells within the RMS may together perturb the normal migration of neuroblasts in Bax-KO mice.

However, the disruption of the glial tube may not be the only reason for the impairment of RMS migration. The glial tube is formed during postnatal development (P7-P14), and the migration of developmentally produced OB neuroblasts at early postnatal ages is independent of or at least less dependent on the RMS (Lois and Alvarez-Buylla, 1994; Lois et al., 1996). However, we also observed a substantial impairment of migration of earlyborn (P4) olfactory neurons in Bax-KO mice. It appears that the increased traffic of neuroblasts in the RMS by prevention of PCD may disrupt the development of the glial tube, which could affect the efficiency of RMS migration. This could also explain the pro- 

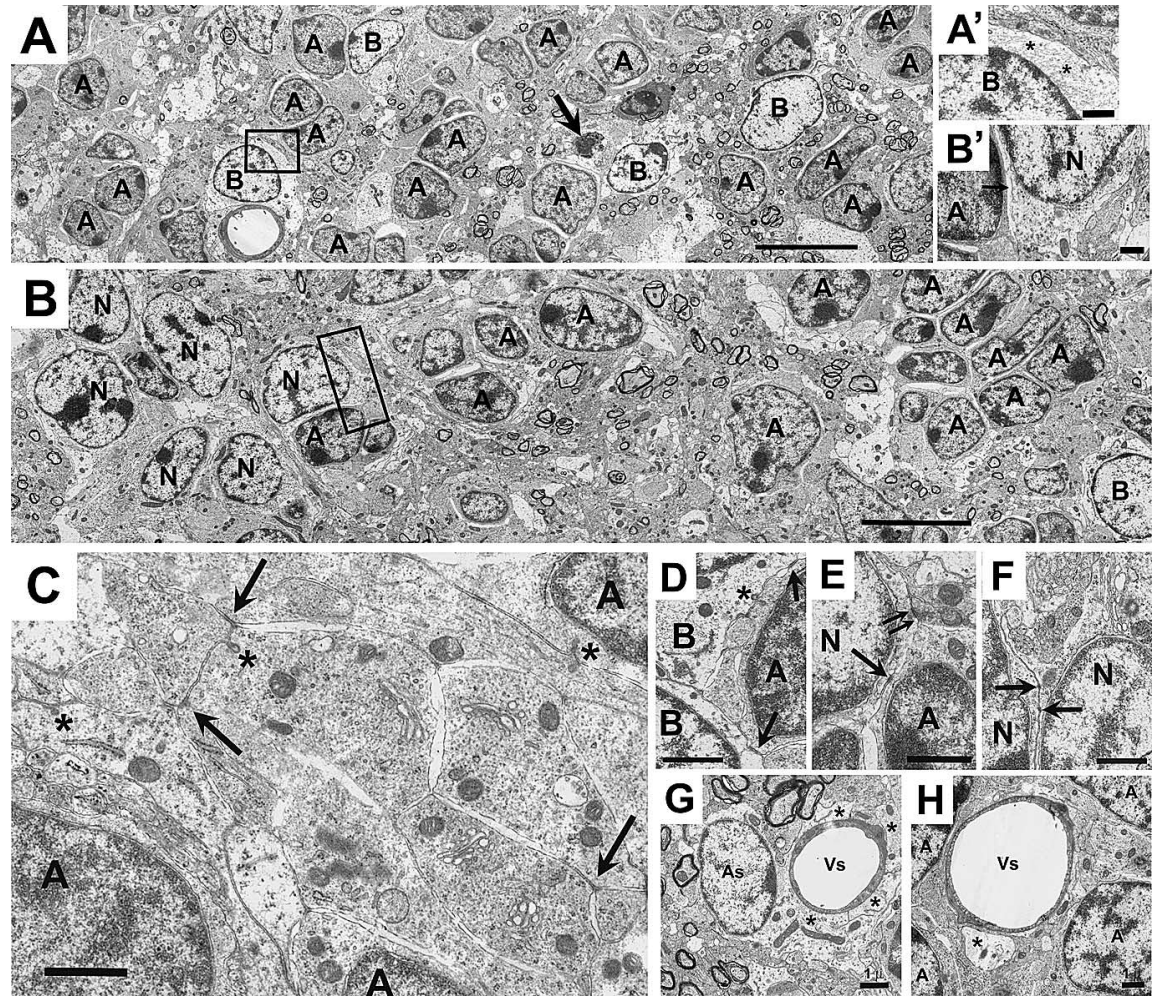

Figure 8. $\quad \boldsymbol{A}$, The RMS of 2-month-old WT mice is composed of migrating neuroblasts (A) interspersed with astrocyte-like glial cells (B). The arrow points to the remnants of a dying cell. $\boldsymbol{A}, \mathrm{B}$-type cell (box) is enlarged in $\boldsymbol{A}^{\prime}$, showing light filamentous cytoplasm and a nucleus heavily rimmed with chromatin typical of astrocytes. $\boldsymbol{B}$, In the RMS of 2-month-old Bax-KO mice, some neuroblasts appear to have ceased migrating and begun differentiation (N). The boxed area in $\boldsymbol{B}$ is enlarged in $\boldsymbol{B}^{\prime}$ to show a typical dense A cell with very sparse cytoplasm surrounded by spaces characteristic of migrating cells, and an N cell, with more differentiated cytoplasm containing some mitochondria, ribosomes, and endoplasmic reticulum, and a nucleus that is lighter and less rimmed with chromatin than B cells and that appears to be an immature neuron. Note that, in the Bax-KO, the $\mathrm{N}$ cells are located to one side of the field across the RMS (N-zone), in which $B$ cells are sparse, whereas $A$ cells and one $B$ cell are located at the other side (A-zone). Scale bars: $\boldsymbol{A}, \boldsymbol{B}, 10 \mu \mathrm{m} ; \boldsymbol{A}^{\prime}, \boldsymbol{B}^{\prime}, 1 \mu \mathrm{m}$. The RMS of both 2-month-old WT and Bax-K0 mice exhibit frequent puncta adherentia. In $C$, a group of WT A cells can be seen with several puncta (arrows); coated vesicle formation is often associated with these structures $\left({ }^{*}\right)$; $\boldsymbol{D}$ illustrates A-B contacts in WT. $\boldsymbol{E}$, Bax-KO mice also exhibit A-N puncta in which these cells are in close proximity (arrow); the $\mathrm{N}$ cell also has a vesicle lined density that may be a forming synapse (double arrow). $\boldsymbol{F}$, Puncta (arrows) between two $\mathrm{N}$ cells. Another striking feature of the Bax-KO is the absence of astrocytic end feet on blood vessels, seen in $\mathbf{G}$ and $\boldsymbol{H}$, which are common in WT, as seen in $\mathbf{G}^{*}{ }^{*}$, Astrocytic process; As, astrocyte; Vs, blood vessel. Scale bars, $10 \mu \mathrm{m}$.

gressive developmental accumulation of migratory deficits during later development of Bax-KO mice.

\section{Cell-autonomous and position-dependent differentiation of RMS neurons}

We found that the migration-defective cells in the $\mathrm{N}$-zone of the RMS expressed markers for mature OB interneurons such as calretinin and GABA, indicating that the fate of these neurons is independent of the local (OB) environment. Consistent with this possibility, the suppression of RMS migration induced by surgical intervention (Jankovski et al., 1998) or GABA treatment (Bolteus and Bordey, 2004) results in the premature detachment of neuroblasts and their early differentiation into $\mathrm{CR}^{+}$ cells. Conversely, although $\sim 1-5 \%$ of adult produced cells become $\mathrm{TH}^{+}$neurons in the periglomerular layer (PGL), none of the ectopically positioned neurons in the Bax-KO RMS exhibited TH-IR, indicating that environmental cues in the OB may be critical for the differentiation of TH neurons. In WT mice, the differentiation of TH neuron occurs in the PGL, although neuroblasts in the RMS also express Pax6 a transcription factor critical for TH neuronal differentiation (Hack et al., 2005; Kohwi et al., 2005). Interestingly, we found

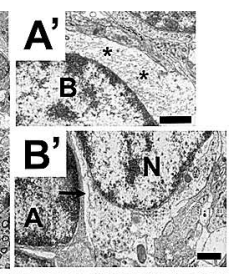

ectopically positioned $\mathrm{TH}^{+}$cells within the GCL of the Bax-KO OB. Although the biological significance of this finding is unclear, it appears that a small fraction of neuroblasts may be able to ectopically differentiate into $\mathrm{TH}$ neurons during their radial migration within the $\mathrm{OB}$ and such errors may be normally corrected by Bax-dependent PCD.

\section{Olfactory function in the absence of PCD}

Because defects in RMS migration in Bax-KO mice resulted in the failure of new cell entry into the $\mathrm{OB}$, we asked whether olfactory behavior is influenced by the absence of PCD. This question was especially interesting because at 3-months new cell entry into the $\mathrm{OB}$ of $\mathrm{Bax}-\mathrm{KO}$ and WT mice is similar, whereas at 12-months of age new cell entry is absent in the Bax-KO OB. Renewal of OB neurons by adult neurogenesis has been proposed to be critical for some olfactory functions such as fine olfactory discrimination and olfactory memory (Gheusi et al., 2000; Lledo et al., 2006). For example, NCAM-KO mice with reduced olfactory neurogenesis exhibited reduced olfactory sensitivity and olfactory memory (Gheusi et al., 2000). Conversely, olfactory enrichment induces an increase in the number of surviving newborn neurons together with enhanced short-term olfactory memory (Rochefort et al., 2002; Rochefort and Lledo, 2005). Furthermore, there is a correlation between the age-dependent decline of adult neurogenesis and fine odorant discrimination, suggesting that adult neurogenesis might regulate rather subtle olfactory functions (Enwere et al., 2004). However, our results do not support this notion. We failed to identify alterations in any of the olfactory behaviors examined in either 3- or 12-month old Bax-KO mice. Because animals in these previous reports exhibited a substantial reduction in the size of the $\mathrm{OB}$ and in the total number of granule neurons (Gheusi et al., 2000), olfactory function may be more closely related to overall neuronal numbers. The dissociation of neurogenesis and olfactory function has also been recently reported in Tenacin-C deficient mice; odor detection was selectively impaired without reduced olfactory neurogenesis (de Chevigny et al., 2006). Furthermore, knock-out mice lacking neuronal nicotinic acetylcholine receptors exhibit increased numbers of adultgenerated neurons but have impaired short-term olfactory memory (Mechawar et al., 2004). Collectively, these results together with our current observations suggest that PCD is dispensable for many aspects of olfactory function and that continuous cell renewal in the OB appears to play only a limited role in olfactory information processing, although we do not exclude the possibility that adult-produced immature $\mathrm{OB}$ neurons may have a unique role in novel odor processing (Magavi et al., 2005). 
A
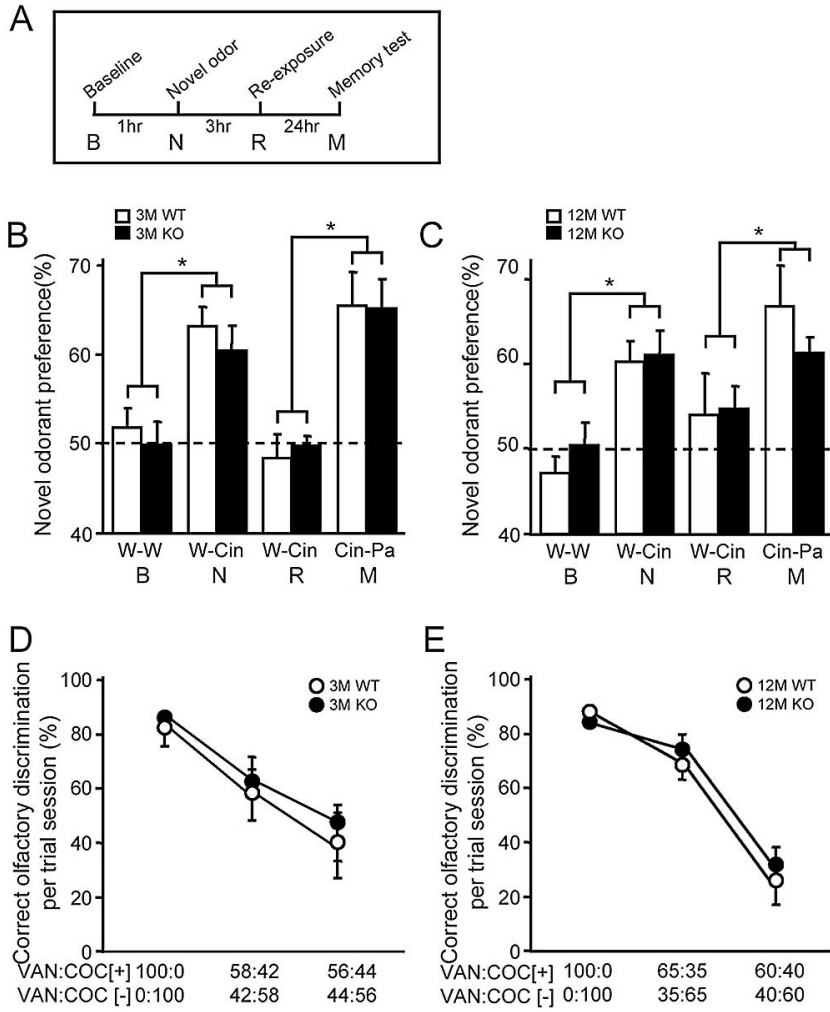

Figure 9. Olfactory behaviors. $A$, Summary of the experimental design. Baseline activity was measured with two identical odorants (B), and $1 \mathrm{~h}$ later a novel odor was presented and the percentage of time approaching to the novel odor was measured (N). Animals were then reexposed to the odor after a 3-h interval (R). The next day, animals were exposed to the familiar odor and a novel odor, and odor preference was measured as an index of olfactory memory (M). $\boldsymbol{B}, \boldsymbol{C}$, Odor discrimination and the memory test, in 3-month-old $(\boldsymbol{B}, n=6)$ or 12-month-old ( $\boldsymbol{C}$, $n=7)$ animals. $\boldsymbol{D}, \boldsymbol{E}$, The fine odor discrimination test in 3-month-old $(\boldsymbol{D}, n=4)$ or 12-monthold $(\boldsymbol{E}, n=5)$ WT and Bax-KO mice. Ratios of vanilla (VAN) and coconut ( $(O C)$ mixtures in water $([+])$ or denotonium benzoate (bitter, $[-])$ containing dishes are represented on the $x$-axis. Mean \pm SEM; ${ }^{*} p<0.05$, Student's $t$ test.

\section{References}

Agasse F, Roger M, Coronas V (2004) Neurogenic and intact or apoptotic non-neurogenic areas of adult brain release diffusible molecules that differentially modulate the development of subventricular zone cell cultures. Eur J Neurosci 19:1459-1468.

Altman J (1969) Autoradiographic and histological studies of postnatal neurogenesis. IV. Cell proliferation and migration in the anterior forebrain, with special reference to persisting neurogenesis in the olfactory bulb. J Comp Neurol 137:433-457.

Alvarez-Buylla A, Lim DA (2004) For the long run: maintaining germinal niches in the adult brain. Neuron 41:683-686.

Alvarez-Buylla A, Garcia-Verdugo JM (2002) Neurogenesis in adult subventricular zone. J Neurosci 22:629-634.

Alvarez-Buylla A, Garcia-Verdugo JM, Tramontin AD (2001) A unified hypothesis on the lineage of neural stem cells. Nat Rev Neurosci 2:287-293.

Anton ES, Ghashghaei HT, Weber JL, McCann C, Fischer TM, Cheung ID, Gassmann M, Messing A, Klein R, Schwab MH, Lloyd KC, Lai C (2004) Receptor tyrosine kinase ErbB4 modulates neuroblast migration and placement in the adult forebrain. Nat Neurosci 7:1319-1328.

Belluzzi O, Benedusi M, Ackman J, LoTurco JJ (2003) Electrophysiological differentiation of new neurons in the olfactory bulb. J Neurosci 23:10411-10418.

Belmadani A, Tran PB, Ren D, Miller RJ (2006) Chemokines regulate the migration of neural progenitors to sites of neuroinflammation. J Neurosci 26:3182-3191.

Belvindrah R, Rougon G, Chazal G (2002) Increased neurogenesis in adult mCD24-deficient mice. J Neurosci 22:3594-3607.

Biebl M, Cooper CM, Winkler J, Kuhn HG (2000) Analysis of neurogenesis and programmed cell death reveals a self-renewing capacity in the adult rat brain. Neurosci Lett 291:17-20.

Bolteus AJ, Bordey A (2004) GABA release and uptake regulate neuronal precursor migration in the postnatal subventricular zone. J Neurosci 24:7623-7631.

Buss RR, Sun W, Oppenheim RW (2006) Adaptive roles of programmed cell death during nervous system development Annu Rev Neurosci 29:1-35.

Carleton A, Petreanu LT, Lansford R, Alvarez-Buylla A, Lledo PM (2003) Becoming a new neuron in the adult olfactory bulb. Nat Neurosci 6:507-518.

Chazal G, Durbec P, Jankovski A, Rougon G, Cremer H (2000) Consequences of neural cell adhesion molecule deficiency on cell migration in the rostral migratory stream of the mouse. J Neurosci 20:1446-1457.

Corotto FS, Henegar JR, Maruniak JA (1994) Odor deprivation leads to reduced neurogenesis and reduced neuronal survival in the olfactory bulb of the adult mouse. Neuroscience 61:739-744.

de Chevigny A, Lemasson M, Saghatelyan A, Sibbe M, Schachner M, Lledo PM (2006) Delayed onset of odor detection in neonatal mice lacking tenascin-C. Mol Cell Neurosci 32:174-186.

del Zoppo GJ, Hallenbeck JM (2000) Advances in the vascular pathophysiology of ischemic stroke. Thromb Res 98:73-81.

Doetsch F (2003) The glial identity of neural stem cells. Nat Neurosci 6:1127-1134.

Doetsch F, Garcia-Verdugo JM, Alvarez-Buylla A (1997) Cellular composition and three-dimensional organization of the subventricular germinal zone in the adult mammalian brain. J Neurosci 17:5046-5061.

Doetsch F, Caille I, Lim DA, Garcia-Verdugo JM, Alvarez-Buylla A (1999) Subventricular zone astrocytes are neural stem cells in the adult mammalian brain. Cell 97:703-716.

Enwere E, Shingo T, Gregg C, Fujikawa H, Ohta S, Weiss S (2004) Aging results in reduced epidermal growth factor receptor signaling, diminished olfactory neurogenesis, and deficits in fine olfactory discrimination. J Neurosci 24:8354-8365.

Fiske BK, Brunjes PC (2001) Cell death in the developing and sensorydeprived rat olfactory bulb. J Comp Neurol 431:311-319.

Gage FH (2002) Neurogenesis in the adult brain. J Neurosci 22:612-613.

Garcia-Verdugo JM, Doetsch F, Wichterle H, Lim DA, Alvarez-Buylla A (1998) Architecture and cell types of the adult subventricular zone: in search of the stem cells. J Neurobiol 36:234-248.

Gheusi G, Cremer H, McLean H, Chazal G, Vincent JD, Lledo PM (2000) Importance of newly generated neurons in the adult olfactory bulb for odor discrimination. Proc Natl Acad Sci USA 97:1823-1828.

Giachino C, De Marchis S, Giampietro C, Parlato R, Perroteau I, Schutz G, Fasolo A, Peretto P (2005) cAMP response element-binding protein regulates differentiation and survival of newborn neurons in the olfactory bulb. J Neurosci 25:10105-10118.

Gritti A, Bonfanti L, Doetsch F, Caille I, Alvarez-Buylla A, Lim DA, Galli R, Verdugo JM, Herrera DG, Vescovi AL (2002) Multipotent neural stem cells reside into the rostral extension and olfactory bulb of adult rodents. J Neurosci 22:437-445.

Hack I, Bancila M, Loulier K, Carroll P, Cremer H (2002) Reelin is a detachment signal in tangential chain-migration during postnatal neurogenesis. Nat Neurosci 5:939-945.

Hack MA, Saghatelyan A, de Chevigny A, Pfeifer A, Ashery-Padan R, Lledo PM, Gotz M (2005) Neuronal fate determinants of adult olfactory bulb neurogenesis. Nat Neurosci 8:865-872.

Hu H, Tomasiewicz H, Magnuson T, Rutishauser U (1996) The role of polysialic acid in migration of olfactory bulb interneuron precursors in the subventricular zone. Neuron 16:735-743.

Jankovski A, Garcia C, Soriano E, Sotelo C (1998) Proliferation, migration and differentiation of neuronal progenitor cells in the adult mouse subventricular zone surgically separated from its olfactory bulb. Eur J Neurosci 10:3853-3868.

Kaplan MS, McNelly NA, Hinds JW (1985) Population dynamics of adultformed granule neurons of the rat olfactory bulb. J Comp Neurol 239:117-125.

Keilhoff G, Becker A, Grecksch G, Bernstein HG, Wolf G (2006) Cell proliferation is influenced by bulbectomy and normalized by imipramine treatment in a region-specific manner. Neuropsychopharmacology 31:1165-1176.

Kirschenbaum B, Doetsch F, Lois C, Alvarez-Buylla A (1999) Adult subven- 
tricular zone neuronal precursors continue to proliferate and migrate in the absence of the olfactory bulb. J Neurosci 19:2171-2180.

Kohwi M, Osumi N, Rubenstein JL, Alvarez-Buylla A (2005) Pax6 is required for making specific subpopulations of granule and periglomerular neurons in the olfactory bulb. J Neurosci 25:6997-7003.

Law AK, Pencea V, Buck CR, Luskin MB (1999) Neurogenesis and neuronal migration in the neonatal rat forebrain anterior subventricular zone do not require GFAP-positive astrocytes. Dev Biol 216:622-634.

Lindsten T, Ross AJ, King A, Zong WX, Rathmell JC, Shiels HA, Ulrich E, Waymire KG, Mahar P, Frauwirth K, Chen Y, Wei M, Eng VM, Adelman DM, Simon MC, Ma A, Golden JA, Evan G, Korsmeyer SJ, MacGregor GR, Thompson CB (2000) The combined functions of proapoptotic Bcl-2 family members bak and bax are essential for normal development of multiple tissues. Mol Cell 6:1389-1399.

Lindsten T, Golden JA, Zong WX, Minarcik J, Harris MH, Thompson CB (2003) The proapoptotic activities of Bax and Bak limit the size of the neural stem cell pool. J Neurosci 23:11112-11119.

Liu Z, Martin LJ (2003) Olfactory bulb core is a rich source of neural progenitor and stem cells in adult rodent and human. J Comp Neurol 459:368-391.

Lledo PM, Alonso M, Grubb MS (2006) Adult neurogenesis and functional plasticity in neuronal circuits. Nat Rev Neurosci 7:179-193.

Lois C, Alvarez-Buylla A (1993) Proliferating subventricular zone cells in the adult mammalian forebrain can differentiate into neurons and glia. Proc Natl Acad Sci USA 90:2074-2077.

Lois C, Alvarez-Buylla A (1994) Long-distance neuronal migration in the adult mammalian brain. Science 264:1145-1148.

Lois C, Garcia-Verdugo JM, Alvarez-Buylla A (1996) Chain migration of neuronal precursors. Science 271:978-981.

Magavi SS, Leavitt BR, Macklis JD (2000) Induction of neurogenesis in the neocortex of adult mice. Nature 405:951-955.

Magavi SS, Mitchell BD, Szentirmai O, Carter BS, Macklis JD (2005) Adultborn and preexisting olfactory granule neurons undergo distinct experience-dependent modifications of their olfactory responses in vivo. J Neurosci 25:10729-10739.

Mandairon N, Jourdan F, Didier A (2003) Deprivation of sensory inputs to the olfactory bulb up-regulates cell death and proliferation in the subventricular zone of adult mice. Neuroscience 119:507-516.

Mechawar N, Saghatelyan A, Grailhe R, Scoriels L, Gheusi G, Gabellec MM, Lledo PM, Changeux JP (2004) Nicotinic receptors regulate the survival of newborn neurons in the adult olfactory bulb. Proc Natl Acad Sci USA 101:9822-9826.

Nakatomi H, Kuriu T, Okabe S, Yamamoto S, Hatano O, Kawahara N, Tamura A, Kirino T, Nakafuku M (2002) Regeneration of hippocampal pyramidal neurons after ischemic brain injury by recruitment of endogenous neural progenitors. Cell 110:429-441.

Nguyen-Ba-Charvet KT, Picard-Riera N, Tessier-Lavigne M, Baron-Van
Evercooren A, Sotelo C, Chedotal A (2004) Multiple roles for slits in the control of cell migration in the rostral migratory stream. J Neurosci 24:1497-1506.

Palmer TD, Willhoite AR, Gage FH (2000) Vascular niche for adult hippocampal neurogenesis. J Comp Neurol 425:479-494.

Parrish-Aungst S, Shipley MT, Erdelyi F, Szabo G, Puche AC (2007) Quantitative analysis of neuronal diversity in the mouse olfactory bulb. J Comp Neurol 501:825-836.

Peretto P, Merighi A, Fasolo A, Bonfanti L (1997) Glial tubes in the rostral migratory stream of the adult rat. Brain Res Bull 42:9-21.

Peters A, Palay S, Webster H (1976) The fine structure of the nervous system. Philadelphia: Saunders.

Petreanu L, Alvarez-Buylla A (2002) Maturation and death of adult-born olfactory bulb granule neurons: role of olfaction. J Neurosci 22:6106-6113.

Petridis AK, El-Maarouf A, Rutishauser U (2004) Polysialic acid regulates cell contact-dependent neuronal differentiation of progenitor cells from the subventricular zone. Dev Dyn 230:675-684.

Rochefort C, Lledo PM (2005) Short-term survival of newborn neurons in the adult olfactory bulb after exposure to a complex odor environment. Eur J Neurosci 22:2863-2870.

Rochefort C, Gheusi G, Vincent JD, Lledo PM (2002) Enriched odor exposure increases the number of newborn neurons in the adult olfactory bulb and improves odor memory. J Neurosci 22:2679-2689.

Saghatelyan A, de Chevigny A, Schachner M, Lledo PM (2004) Tenascin-R mediates activity-dependent recruitment of neuroblasts in the adult mouse forebrain. Nat Neurosci 7:347-356.

Scotto-Lomassese S, Strambi C, Strambi A, Aouane A, Augier R, Rougon G, Cayre M (2003) Suppression of adult neurogenesis impairs olfactory learning and memory in an adult insect. J Neurosci 23:9289-9296.

Shi J, Parada LF, Kernie SG (2005) Bax limits adult neural stem cell persistence through caspase and IP3 receptor activation. Cell Death Differ 12:1601-1612.

Simard M, Arcuino G, Takano T, Liu QS, Nedergaard M (2003) Signaling at the gliovascular interface. J Neurosci 23:9254-9262.

Sun W, Gould TW, Vinsant S, Prevette D, Oppenheim RW (2003) Neuromuscular development after the prevention of naturally occurring neuronal death by Bax deletion. J Neurosci 23:7298-7310.

Sun W, Winseck A, Vinsant S, Park OH, Kim H, Oppenheim RW (2004) Programmed cell death of adult-generated hippocampal neurons is mediated by the proapoptotic gene Bax. J Neurosci 24:11205-11213.

White FA, Keller-Peck CR, Knudson CM, Korsmeyer SJ, Snider WD (1998) Widespread elimination of naturally occurring neuronal death in Baxdeficient mice. J Neurosci 18:1428-1439.

Winner B, Cooper-Kuhn CM, Aigner R, Winkler J, Kuhn HG (2002) Longterm survival and cell death of newly generated neurons in the adult rat olfactory bulb. Eur J Neurosci 16:1681-1689. 